\title{
Language Selectivity in Lexical Access: an Experimental Study on Bilinguals
}

Fatma Demiray

is currently Instructor Dr. at the School of Foreign Languages, AIBU. Correspondence: Instr.Dr. Fatma Demiray, Abant Izzet Baysal University, School of Foreign Languages.14280 Gölköy/Bolu-Turkey. E-mail: demiray f@ibu.edu.tr /demirayfatma@gmail.com Phone:

$+903742541000$

Dilek Peçenek

is currently Assoc. Prof. at Ankara University, Department of Linguistics. Correspondence: Assoc. Prof. Dilek Peçenek, Ankara University, Department of Linguistics, Ankara/Turkey. E-mail: pecenek@ankara.edu.tr

\begin{abstract}
In this study, the locus of language selection in bilingual lexical access is investigated based on some basic factors such as first languages, second language proficiency, age of acquisition and multilingualism. In particular, this study explores competition between bilinguals' languages and proposes two language selection models; Inhibitory Control Model (Green, 1998) and Concept Selection Model (La Heij, 2005). In experiment 1, the participants were asked to perform a word translation task from their second language (L2) to first language (L1). Each target was accompanied by a distracter item in the form of a picture or a word which was related/unrelated to the target word semantically. As a result, all participants translated target words faster when they are accompanied with semantically related/unrelated word distracters than picture distracters. On the other hand, they translated target words faster when they are accompanied with unrelated word distracters than related word distracters. Finally, they translated target words faster when they are accompanied with related picture distracters than unrelated picture distracters. In experiment 2, participants were asked to perform a switching task with the numbers in their first language and second language according to the background color of the digits. Finally, the language switching cost was larger when switching from L2 to L1 than vice versa. The results have shown that while the factors such as L1 andage of acquisition do not affect the locus of language selection during lexical access, proficiency in L2 and multilingualism factors affect the locus of language selection.
\end{abstract}

Keywords: Bilingualism, Inhibitory Control Model, Concept Selection Model, Lexical Access

\section{Bilingual Lexical Access and Speech Production}

Bilingual lexical access and speech utterance terms require that language to be chosen to produce can be determined in advance of speech planning. When an Italian- English bilingual is asked to name a picture of a tree in English, he/she will come up with the word table. The process that makes the connection between the "idea" table and the word table is often referred to as lexical access (La Heij, 2005).

Lexical access is only a small part of bilingual language production but a very fundamental step because it bridges the gap between nonverbal thought world and language world (La Heij, 2005; Bloem \& La Heij, 2003). Besides, the lexicons in both languages share a common conceptual system. That is, the concept of a tree is the same in both languages but happens to be mapped on to two lexical entries (table and tavolo) (Schwieter, 2007; Kroll \& Stewart, 1994; Kroll \& de Groot, 1997).

As it is mentioned, several lexical representations are activated due to spreading activation from the semantic system to the lexical level and thus a selection mechanism is needed. In this mechanism, the semantic system activates both the word that matches the intended meaning and other related items (see Figure 1) (Costa \& Santesteban, 2004). Two selection processes are commonly assumed in language production models. These are the selection of conceptual information to be lexicalized (concept selection) and the selection of the response word from a set of activated words (lexical selection) (La Heij, 2005, p. 290). 


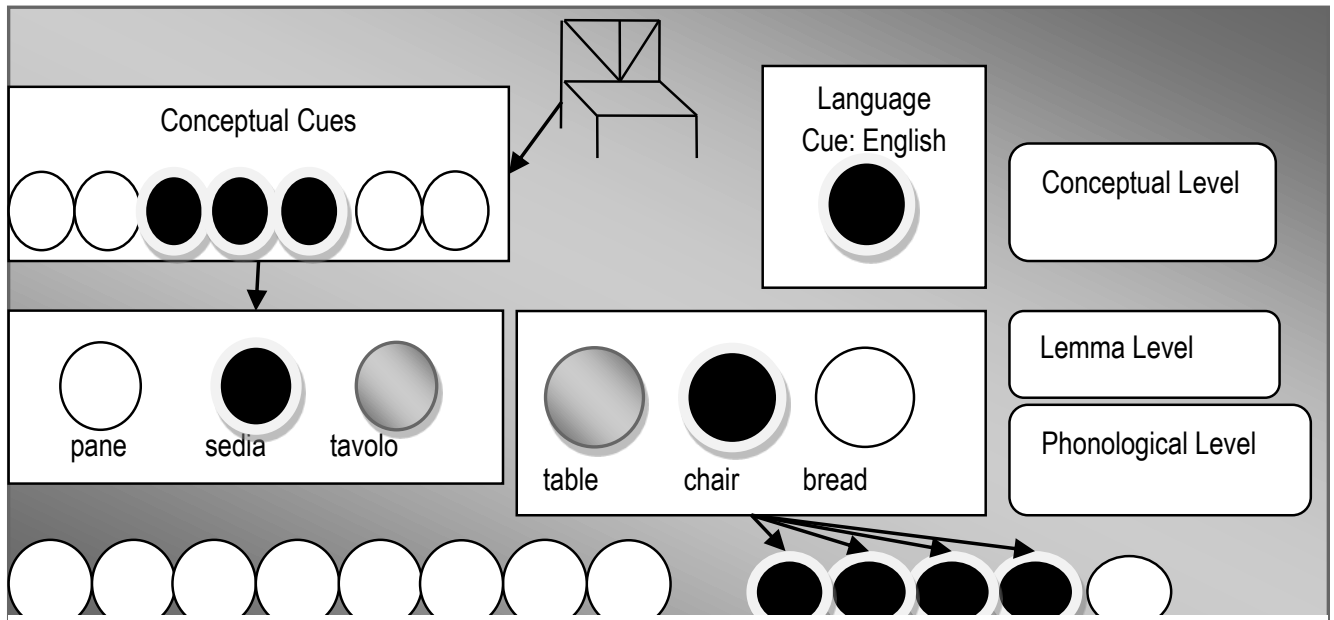

Figure 1. A model of Bilingual Language Production (adapted from Poulisse \& Bongaerts, 1994 \& Hermans, 2000) (cited in Kroll, Bobb \& Wodniecka, 2006, p.120).

\section{1 Language Specific Selection and Concept Selection Model}

As in Levelt's (2001) proposal lexical access occurs automatically in the sense that it delivers a winner depending on the information in preverbal message and "complex access, simple selection" idea is emphasized. Costa (2005) assumes that during speech planning semantic system activates lexical nodes in both languages however, these nodes do not compete for selection because they have been already selected in preverbal message, in other words in conceptual level. Finally, according to Concept Selection Model (CSM), the most highly activated lexical node in the target language is chosen (Costa, 2005; Kroll, Bob \& Wodniecka, 2006; Fishman, 2001; Francis, 2000; La Heij, 2005). Therefore, this selection process is not based on inhibition or suppression as competition does not occur between languages but within languages (see Figure 2).

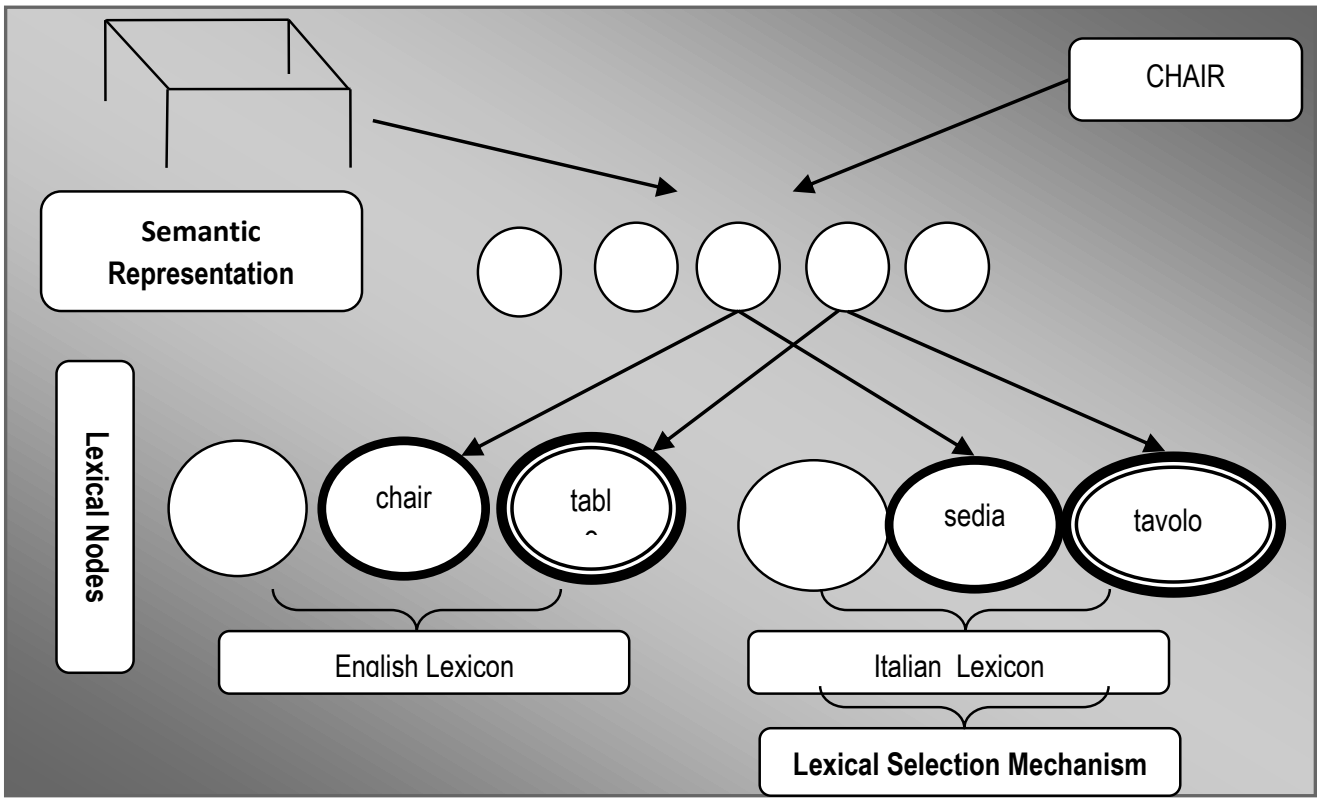


Some researchers who favor non-specific language selection are opposed to language specific selection hypothesis (Green, 1998; Caramazza, 1997; De Bot, 1992). They assume that there is cross-language activity the languages compete for selection. In other words, lexical nodes in both languages are activated by semantic system (see Figure 3 ).

The basic hypothesis of Inhibitory Control Model (ICM) is that the selection of one language is only possible after suppression or inhibition of nontarget language. This inhibition is the main reason for longer Response Times (RTs) and more errors. Moreover, more dominant language will take longer time to produce because it has a larger system than weaker language and it will need stronger inhibition.

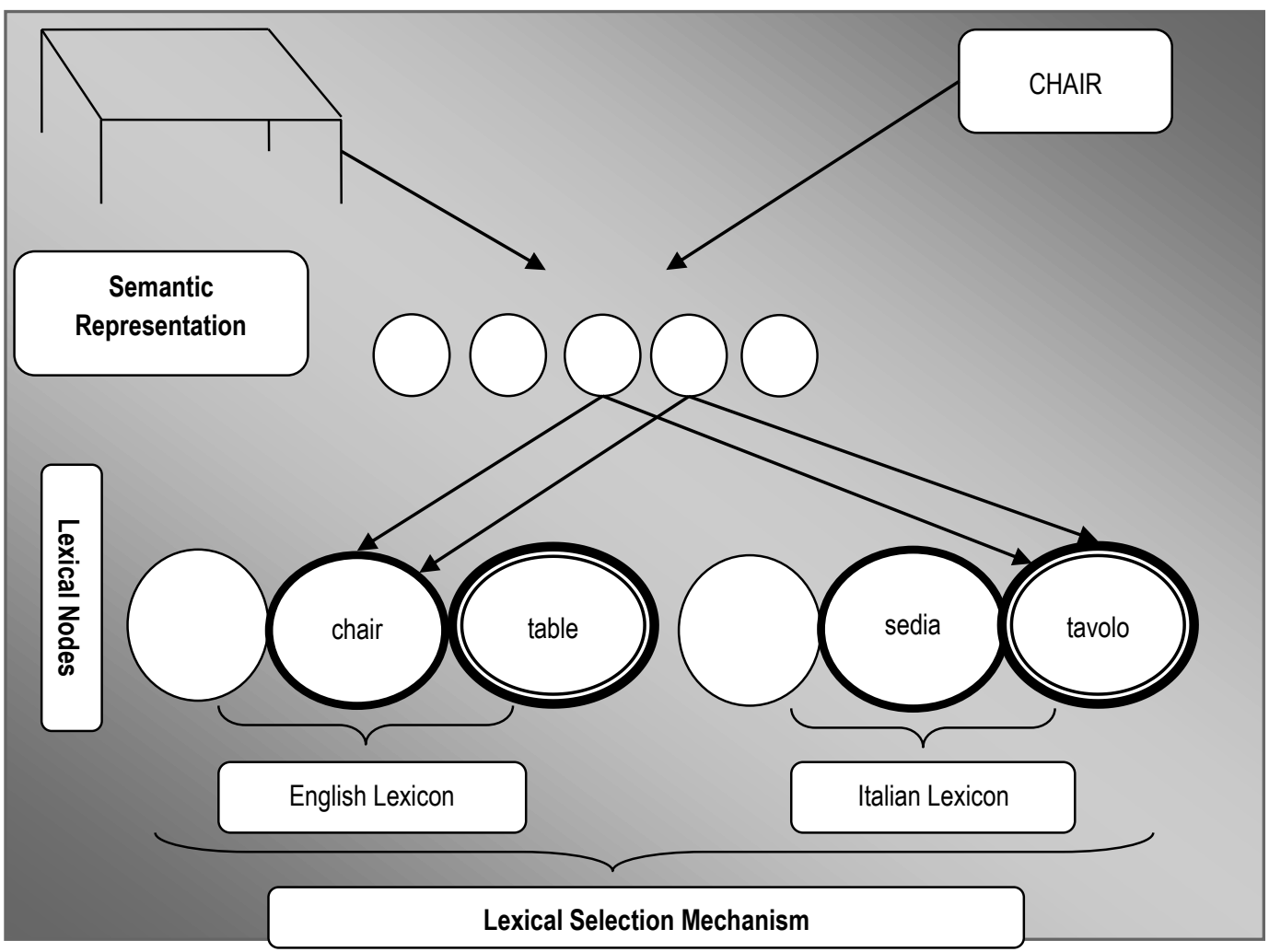

Figure 3. Nonspecific Language Selection Model (Costa, Miozzo \& Caramazza, 1999, p.370)

\section{Method of the Study}

This study in which the lexical access and language selection process are supposed to analyze on undergraduate or graduate English learners of Turkish and Italian is based on experimental approach and the data has been observed quantitatively. In this frame, firstly, Oxford Quick Placement Test (OQPT) is applied to determine the proficiency level in L2 of the participants. Afterword, language history questionnaire is performed to reach the participants' demographic information and all participants are grouped into two in terms of L1, L2 Proficiency Level, L2 Age of Acquisition and Multilingualism. After then, two experiments have been designed in the name of Word Translation Task based on CSM (La Heij, 2005) and Numeral Task based on ICM (Green, 1998). 


\section{1 Overview of the Experiments}

The goal of the present study is to examine the underlying processes of bilingual lexical selection and speech production in terms of the nature of bilinguals (i. e. varying types of bilinguals, L2 proficiency level, age of acquisition and multilingualism). In particular, the experiments investigate the loci of language selection and competition based on CSM and ICM. These two distinct theories seek to explore whether speech production are found at conceptual or lexical level.

In Experiment 1, it is investigated that target language is established at the initial stages of the lexical process and other mechanisms such as inhibition are not necessary during speech production process. In the experiment, Italian-English and Turkish-English bilinguals who translated English words into Italian or Turkish are included. Each target word was accompanied by a distracter item in the form of a picture or a word which semantically related or unrelated to the target. To understand whether factors of bilingualism affect these lexical process or the loci of selection and competition, four kinds of bilingual groups are included comparatively. If participants take longer to translate when distracter items are in the form of pictures, it can be concluded that there is a competition at the conceptual level (because pictures activate their conceptual representation). However, if participants are slower to translate when the distracters are words, it can be assumed that there is a competition at the lexical level of the speech production process.

In Experiment 2, the main goal is to examine whether bilinguals suppress the nonrelevant language during speech production. Recall that IC Model expresses the fact that there is a difference between the size of L1 and L2 and that is the reason why more time is required when switching from L2 to $L 1$ than vice versa. Inhibitory mechanism during language switching appears and the words in the nonrelevant language are inhibited in order to produce the target language. This experiment consists of numeral task (from 0 to 9) with language switches. Bilinguals name the digits according to the background color which is seen on the computer screen. If the digits are presented with a blue background color they name them in English. If they are presented with a yellow background color, they name them in Italian (for Italian-English bilinguals) or in Turkish (for Turkish-English bilinguals). All numbers are presented in short lists of switch or nonswitch trials. If participants need more time switching from L2 to $L 1$ than vice versa, it can be assumed that there is a competition at lexical level.

\section{2 Oxford Quick Placement Test and Language History Questionnaires}

OQPT (Allan, 1992) was conducted to explore the bilinguals' proficiency levels and Language History Questionnaire was used to reach some information about participants' background knowledge about language (s). It was taken from Schwieter (2007) and Marian, Blumfeld \& Kaushanskaya (2007) and adapted after pilot study. In this questionnaire, twenty five items were presented to explore L2 early and late age of acquisition of bilinguals and bilingual or multilingual participants.

Additional information about their language backgrounds such as age, use of languages, self-rated scores for reading, writing, listening, speaking and the other languages which have been learnt after second languages of them was obtained.

\section{3 Participants and Grouping}

A total of 54 participants were recruited from the graduate or undergraduate students who were studying at Roma Tre University, Italy and Ankara University, Turkey. They have different language backgrounds, L2 age of acquisition and knowledge of other languages except from English (L2).

Fifty-four participants took part in the experiments. Participants in Italy were native speakers of Italian and learning English for an average 7 years. These participants were receiving formal training in English as a second language. Participants in Turkey were native speakers of Turkish and learning English for an average of 10 years. Twenty six participants were living in Italy, the rest of them were living in Turkey. Participants from different countries were considered to be L2 learners or late-bilinguals of Italian-English or Turkish-English.

According to OQPT results, the number of the highly and low proficient bilinguals in L2 was twenty-seven to twenty-seven. Twenty two participants acquired the second language in early ages (before 7), thirty two of them in late ages (after 7). Besides, thirty one of the participants only knew second language (English), twenty three of them knew other languages such as German or Arabic for Turkish participants and French or Spanish for Italian participants (see Table 1). 
Table 1. Descriptive Statistics for the Participant Groups

\begin{tabular}{|c|c|c|c|c|}
\hline & L1 Turkish & & L1 Italian & \\
\hline & $\begin{array}{l}\text { L2 Low } \\
\text { Proficiency }\end{array}$ & $\begin{array}{l}\text { L2 High } \\
\text { Proficiency }\end{array}$ & $\begin{array}{l}\text { L2 Low } \\
\text { Proficiency }\end{array}$ & $\begin{array}{l}\text { L2 High } \\
\text { Proficiency }\end{array}$ \\
\hline $\mathbf{N}$ & 16 & 12 & 11 & 15 \\
\hline Age Mean & 18.44 & 26.67 & 19.73 & 27.33 \\
\hline Age Range & $17-21$ & $23-31$ & $17-25$ & $24-32$ \\
\hline OQPTResults & 39.31 & 54.75 & 36.73 & 54.07 \\
\hline L2 Age of Acq. & 9.25 & 5.83 & 8.45 & 5 \\
\hline L2 Reading & 4.25 & 8.83 & 4.55 & 8.93 \\
\hline L2 Writing & 3.94 & 8.08 & 3.82 & 8.2 \\
\hline L2 Speaking & 3.63 & 9 & 3.45 & 8.87 \\
\hline L2 Listening & 4 & 8.42 & 3.45 & 8.8 \\
\hline L2 Self-Expression & 3 & 8.92 & 4.27 & 8.87 \\
\hline Level Mean & 3.76 & 8.65 & 3.9 & 8.73 \\
\hline L1 Speaking & 10 & 10 & 10 & 10 \\
\hline L2 Speaking & 3.56 & 9.33 & 3.82 & 9.6 \\
\hline L3 Speaking & 1.38 & 1,5 & 1.36 & 1.47 \\
\hline L3 Average & 2 & 6.84 & 2.15 & 7.46 \\
\hline
\end{tabular}

\section{Experiment 1: Word Translation Task}

\section{1 Materials}

Thirty two high frequency English words were selected. The target words in the experiments were taken from Bloem and La Heij (2003) and after the pilot study they were adapted (see Appendix A and B for a description). Each of the target words were presented with a semantically related or unrelated words or pictures. For example, the target word DOG (to be translated into Italian as "cane" or into Turkish as "köpek") was accompanied by the picture of a peach or by the word "pesca" (Italian translation equivalent of peach) or "şeftali" (Turkish translation equivalent of peach) in an unrelated context. However, in the related context the same target word DOG was accompanied by the picture of cat or by the word "gatto" (the Italian translation equivalent of cat) or "kedi" " (the Turkish translation equivalent of cat) in a related context. English target words were seen one by one on the computer screen in black-lower case and the distracters were presented in black-lower case immediately over the target words. Half of the participants started the experiment with picture distracters, the other half started with word distracters.

\section{2 Procedure}

The participants were tested individually in a soundproof room at each university. Firstly in a written and then orally, they were asked to translate $\mathrm{L} 2$ words into $\mathrm{L} 1$ as fast as possible. Each participant was given a series of 32 trials two times and one of them was given with related distracters, the other was given with unrelated distracters. First, a fixation point for $500 \mathrm{~ms}$. appeared on the computer screen. Next the stimulus appeared and remained for $2000 \mathrm{~ms}$. If the participant did not 
give any answer during this time, the next trial was seen. The researcher took notes for true and false responses simultaneously and also used voice recorder to indicate and judge the responses later again.

\section{3 Data analysis}

Response latencies of only correct responses (in L1 or L2) were included in the statistical analyses. There are two main variables as picture-word or related-unrelated contexts. The analyses were conducted to each bilingual group separately and T-test was conducted in four phases: a) L1, b) L2 age of acquisition, c) Proficiency level and d) Multilingualism.

\section{4 Results and Discussion}

The results gathered from word translation task to analyze locus of language selection and competition in terms of CSM were investigated on the basis of context (word or picture) and relatedness (related or unrelated). As seen in Table 2, the statistics have shown there was a significant main effect for context $(t(107)=-5.44, p=0.000)$ that is, participants have more difficulty in translating target words when accompanied with pictures (1091 ms. ) than words (1026ms. ). On the other hand, the same significant effect cannot be seen in relatedness $(t(107)=-0.31, p=0.755)$. This suggests that reaction times for translating target words when they are accompanied by related $(1057 \mathrm{~ms}$. ) or unrelated $(1060 \mathrm{~ms}$. ) context were nearly same. It can be understood from these results that words created semantic interference while pictures induced semantic facilitation.

Table 2. Paired Samples Statistics for Context (word-picture) and Relatedness (related-unrelated) in Experiment 1

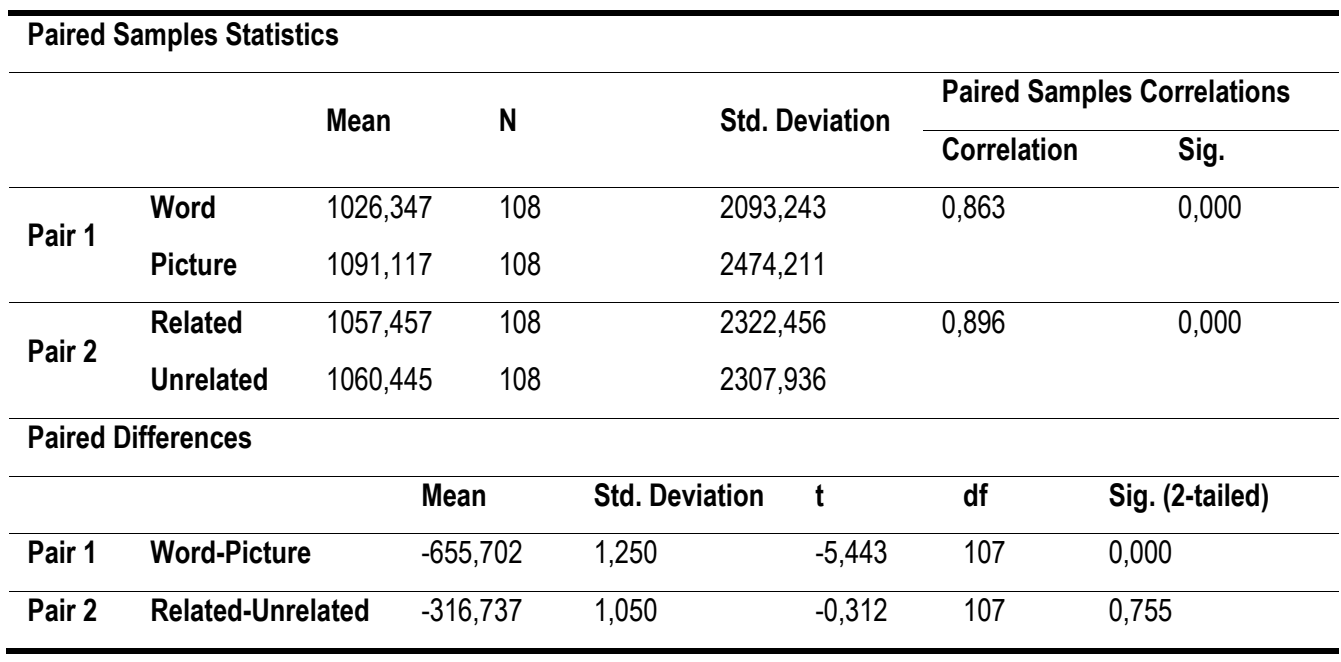

\section{4. 1 L1 Factor and Lexical Access}

As a main goal of this experiment, to see whether L1 factor affects the locus of language selection and lexical access process, the participants were grouped into two; English learners of Italian and Turkish. What is appeared from the mean RTs is that all participants were slower when translating target words in picture contexts than word contexts (see Table 3). While it is investigated whether semantic relatedness effect (SRE) differs according to the type of bilinguals, it can be concluded that context words induce semantic interference $(-10 \mathrm{~ms}$, $-24 \mathrm{~ms}$. ) whereas context pictures induce semantic facilitation (+22ms. , $+26 \mathrm{~ms}$. ). As illustrated in Figure 4, in an unrelated or related context, there is a significant difference 
between L1 Turkish and Italian participants, however, the semantic relatedness effect is the same for both experimental groups.

According to the independent samples T-test results, there is a significant main effect between participants in terms of word $(t(106)=6.01, p=0.000)$, picture $(t(106)=4.39, p=0.000)$, related $(t(106)=5.07, p=0.000)$ and unrelated $(t(106)=4$. $94, p=0.000$ ) context. In other words, Italians were faster for all contexts than Turkish participants. To analyze the main effect of the distracters, Turkish and Italian participants are examined separately (see Table 4 and Table 5).

Table 3. Mean RTs (ms. ), Accuracy (in percent) and SRE for L2 Learners of Italian and Turkish in Experiment 1

\begin{tabular}{lllllllll}
\hline & L1 Italian & \multicolumn{9}{c}{ L1 Turkish } \\
& Word & & Picture & Word & Picture & \\
& Rt & Acc. & Rt & Acc. & Rt & Acc. & Rt & Acc. \\
\hline Unrelated & 912 & 1,9 & 1002 & 1,7 & 1115 & 1,1 & 1197 & 2,3 \\
Related & 922 & 1,6 & 980 & 1,5 & 1139 & 2,3 & 1171 & 1,4 \\
Sre & -10 & & 22 & & -24 & & 26 & \\
\hline
\end{tabular}

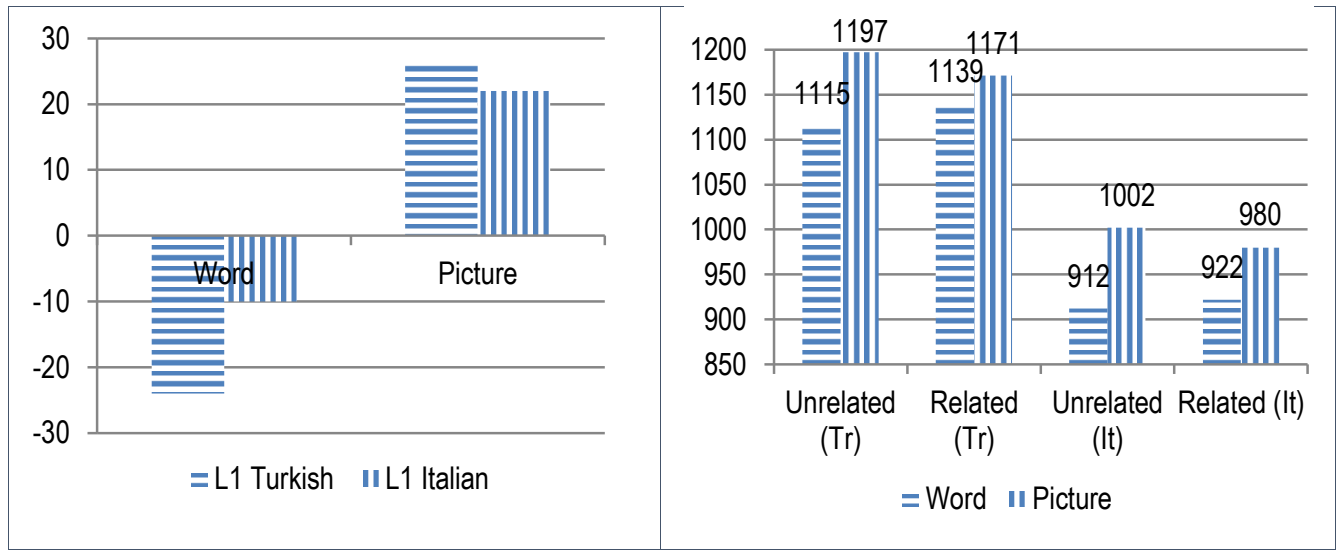

Figure 4. SRE and RTs (in ms. ) for L2 learners of Italian and Turkish in Experiment 1

Paired samples statistics were included for the reason context and relatedness data were collected from each participant group. L1 Turkish participants' mean RTs in picture context is more than word context $(t(55)=-3.453, p=0.000, r=0.811)$, $L 1$ Italian participants also have similar RTs mean $(t(51)=-4.233, p=0.000, r=0.861)$. When relatedness effect is analyzed, both L1 Turkish $(t(55)=-0.04, p=0.971, r=0.850)$ and Italian participants $(t(51)=-0.419, p=0.000, r=0.891)$ have similar results. Consequently, similar effects were reported for both groups and the results support CSM regardless of what type of bilingual may be. In other words, lexical access occurs at conceptual level.

Table 4. Paired Samples Statistics for L2 Learners of Turkish in Experiment 1

\section{Paired Samples Statistics}




\begin{tabular}{|c|c|c|c|c|c|c|}
\hline & & \multirow[b]{2}{*}{ Mean } & \multirow[b]{2}{*}{$\mathbf{N}$} & \multirow[b]{2}{*}{ Std. Deviation } & \multicolumn{2}{|c|}{ Paired Samples Correlation } \\
\hline & & & & & Correlation & Sig. \\
\hline \multirow{2}{*}{ Pair 1} & Word & 1127,534 & 56 & 1753,289 & 0,811 & 0,000 \\
\hline & Picture & 1184,921 & 56 & 2125,853 & & \\
\hline \multirow{2}{*}{ Pair 2} & Related & 1155,963 & 56 & 1972,677 & 0,850 & 0,000 \\
\hline & Unrelated & 1156,491 & 56 & 1967,095 & & \\
\hline
\end{tabular}

\section{Paired Samples T-test}

\begin{tabular}{lllllll}
\hline & & \multicolumn{2}{l}{ Paired Differences } & & & \\
& & Mean & Std. Deviation & $\mathbf{t}$ & df & Sig. (2-tailed) \\
\hline Pair 1 & Word - Picture & $-573,867$ & 1243,669 & $-3,453$ & 55 & 0,001 \\
\hline Pair 2 & Related - Unrelated & $-527,661$ & 1079,440 & $-0,037$ & 55 & 0,971 \\
\hline
\end{tabular}

Table 5. Paired Samples Statistics for L2 learners of Italian in Experiment 1

\begin{tabular}{|c|c|c|c|c|c|c|c|}
\hline \multicolumn{8}{|c|}{ Paired Samples Statistics } \\
\hline & & \multirow[b]{2}{*}{ Mean } & \multirow[b]{2}{*}{$\mathbf{N}$} & & & Paired Sam & es Correlations \\
\hline & & & & \multicolumn{2}{|c|}{ Std. Deviation } & Correlation & Sig. \\
\hline \multirow[t]{2}{*}{ Pair 1} & Word & 917,203 & 52 & \multicolumn{2}{|c|}{1881,146} & 0,861 & 0,000 \\
\hline & Picture & 991,586 & 52 & \multicolumn{2}{|c|}{2447,878} & & \\
\hline \multirow[t]{2}{*}{ Pair 2} & Related & 951,390 & 52 & \multicolumn{2}{|c|}{2215,314} & 0,891 & 0,000 \\
\hline & Unrelated & 957,400 & 52 & \multicolumn{2}{|c|}{2214,369} & & \\
\hline \multicolumn{8}{|c|}{ Paired Samples $T$-test } \\
\hline \multicolumn{8}{|c|}{ Paired Differences } \\
\hline & & \multicolumn{2}{|c|}{ Mean } & Std. Deviation & $t$ & df & Sig. (2-tailed) \\
\hline Pair 1 & Word-Picture & \multicolumn{2}{|c|}{$-743,834$} & 1267,058 & $-4,233$ & 51 & 0,000 \\
\hline Pair 2 & Related-Unrelated & \multicolumn{2}{|c|}{$-601,014$} & 1035,367 & $-0,419$ & 51 & 0,677 \\
\hline
\end{tabular}

\section{4. 2 L2 Proficiency Level Factor and Lexical Access}

To see L2 Proficiency Level affects the locus of selection and competition in the process of L2 lexical access, the participants were categorized into two; low proficient and highly proficient bilinguals in L2. As interpreted in Table 6 and Figure 5, when mean RTs are analyzed, while low proficient bilinguals translate target words faster when they are accompanied with unrelated word context $(1216 \mathrm{~ms}$. ) than related $(1272 \mathrm{~ms}$. ), high proficient bilinguals translate slower target words when they are accompanied with unrelated word context $(814 \mathrm{~ms}$.) than related $(800 \mathrm{~ms}$. ). At this point, L2 proficiency does not already support the hypothesis that emphasize language selectivity is at the conceptual level. However, after several significant interactions and t-test statistics it can be reached the objective results. 
According to the independent samples test results, there is a significant main effect between the groups on the basis of word $(t(106)=11.275, p=0.000)$, picture $(t(106)=13.694, p=0.000)$, related $(t(106)=12.057, p=0.000)$ and unrelated $(t$ $(106)=12.093, p=0.000)$ context. That shows that, high proficient bilinguals were faster than low proficient bilinguals as expected. To analyze the main overall effect of the proficiency on lexical access, both groups are analyzed separately with paired samples test.

Table 6. Mean RTs (ms. ), Accuracy (in percent) and SRE for L2 Low and Highly Proficient Bilinguals in Experiment 1

\begin{tabular}{lllllllll}
\hline & L2 LowProficiency & \multicolumn{7}{l}{ L2 HighProficiency } \\
& Word & & Picture & Word & \multicolumn{3}{c}{ Picture } \\
& Rt & Acc. & Rt & Acc. & Rt & Acc. & Rt & Acc. \\
\hline Unrelated & 1216 & 1,5 & 1278 & 1,8 & 814 & 1,5 & 932 & 2,2 \\
Related & 1272 & 2 & 1252 & 1,6 & 800 & 1,8 & 904 & 2,5 \\
Sre & -56 & & +26 & & +14 & & +28 & \\
\hline
\end{tabular}

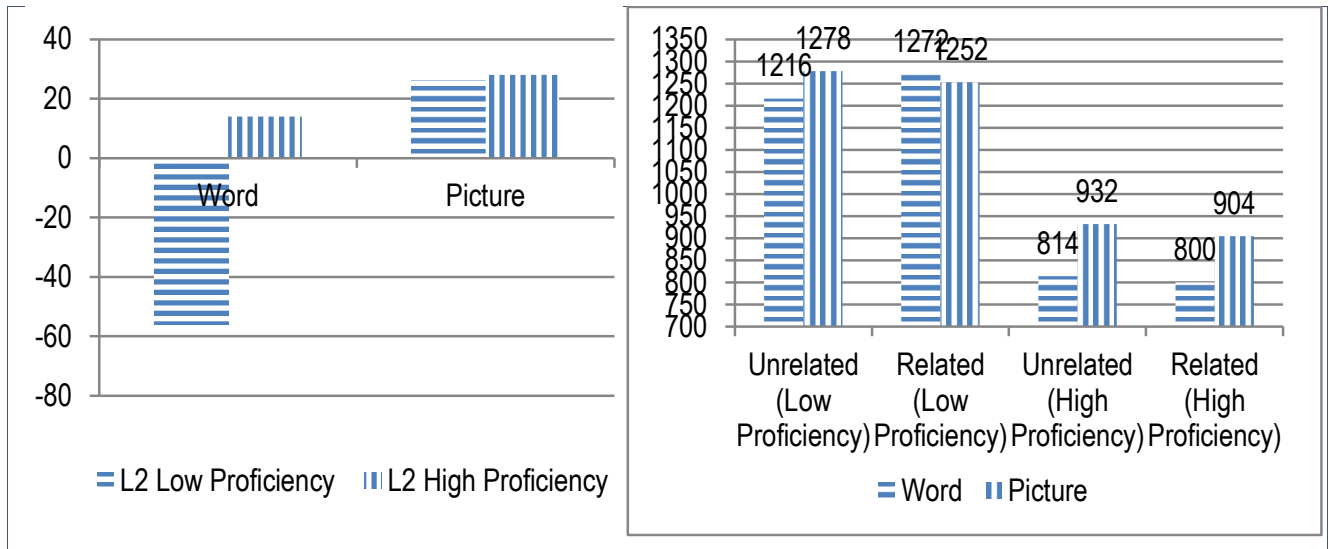

Figure 5. SRE and RTs (in ms. ) for L2 Low Highly Proficient Bilinguals in Experiment 1

Paired samples statistics in Table 7 and 8 are included for the same reason mentioned in $\mathrm{L} 1$ and language selection. There are several significant interactions which should be reported and emphasized. Firstly, for context and relatedness, only low proficient bilinguals could not get significant effect for context $(t(53)=-5.72, p=0.776, r=0.624)$ and for relatedness $(t(53)=$ $-0.14, p=0.886, r=0.769)$. However, high proficient bilinguals could get significant effect only for context $(t(53)=-1.809$, $p=0.004, r=0.750)$ not for relatedness $(t(53)=-0.31, p=0.756, r=0.729)$.

All in all, low and highly proficient bilinguals are affected from different lexical selection processes. Thus, it can be hypothesized that low proficient bilinguals are probably using inhibitory control mechanism to be able to choose the correct language since the language cues in L2 may enter the selection process only after the suppressing of nontarget language nodes.

Finally, it should be emphasized that after the second experiment on ICM, it will be possible to reach a final and exact result about lexical selection process of them. 
Table 7. Paired Samples Statistics for L2 Low Proficient Participants in Experiment 1

\section{Paired Samples Statistics}

\begin{tabular}{lllllll}
\hline & & & & & \multicolumn{2}{c}{ Paired Samples Correlation } \\
\cline { 6 - 7 } & & Mean & N & Std. Deviation & Correlation & Sig. \\
\hline \multirow{2}{*}{ Pair 1 } & Word & 1244,123 & 54 & 1503,705 & 0,624 & 0,000 \\
& Picture & 1265,665 & 54 & 1690,411 & & \\
\hline \multirow{2}{*}{ Pair 2 } & Related & 1262,264 & 54 & 1694,468 & 0,769 & 0,000 \\
& Unrelated & 1247,524 & 54 & 1687,400 & & \\
\hline
\end{tabular}

\section{Paired Samples T-test}

\begin{tabular}{|c|c|c|c|c|c|c|}
\hline & & \multicolumn{5}{|c|}{ Paired Differences } \\
\hline & & Mean & Std. Deviation & $t$ & df & Sig. (2-tailed) \\
\hline Pair 1 & Word - Picture & $-1085,420$ & 1394,759 & $-5,719$ & 53 & 0,776 \\
\hline Pair 2 & Related - Unrelated & $-2259,76$ & 1150,254 & $-0,144$ & 53 & 0,886 \\
\hline
\end{tabular}

Table 8. Paired Samples Statistics for L2 Highly Proficient Participants in Experiment 1

\section{Paired Samples T-test Statistics}

Paired Samples Correlation

\begin{tabular}{lllllll} 
& & Mean & N & Std. Deviation & Correlation & Sig. \\
\hline \multirow{2}{*}{ Pair 1 } & Word & 807,404 & 54 & 1326,957 & 0,750 & 0,000 \\
& Picture & 918,003 & 54 & 1266,948 & & \\
\hline \multirow{2}{*}{ Pair 2 } & Related & 852,666 & 54 & 1311,833 & 0,729 & 0,000 \\
& Unrelated & 873,741 & 54 & 1292,375 & &
\end{tabular}

\section{Paired Samples T-test}

\begin{tabular}{lllllll}
\hline & & \multicolumn{2}{l}{ Paired Differences } & & \\
& & Mean & Std. Deviation & $\mathbf{t}$ & $\mathbf{d f}$ & Sig. (2-tailed) \\
\hline Pair 1 & Word - Picture & $-2259,820$ & 918,143 & $-1,809$ & 53 & 0,004 \\
\hline Pair 2 & Related - Unrelated & $-4074,980$ & 958,627 & $-0,312$ & 53 & 0,756 \\
\hline
\end{tabular}

\section{4. 3 Age of Acquisition Factor and Lexical Access}

Supposing that highly proficient bilinguals acquired language in an early age and low proficient bilinguals in a late age, the participants were grouped into two. However, it is surprising that some highly proficient bilinguals acquired the language in a late age during their staying in an English native country for education or other reasons. Similarly, some of low proficient bilinguals acquired the language in an early stage however, since they did not use it productively, they probably forgot it. Thus they were grouped again according to the results of questionnaire. When analyzed their mean RTs (as Table 9 and Figure 6 illustrate), those in late age of acquisition translated target words in context or relatedness effect slower than those 
in early age of acquisition. This interpretation shows the parallel results to the hypothesis of CSM. In other words, the participants in each group select language at conceptual level. Just as $L 1$, age of acquisition independent samples analyses show that there was an overall main effect for word $(t(106)=-7.895, p=0.000)$, picture $(t(104,781)=-9,145, p=0,000)$, related $(t(105,605)=-8,468, p=0,000)$ and unrelated $(t(105,99)=-8,694, p=0,000)$ context.

Table 9. Mean RTs (ms. ), Accuracy (in percent) and SRE for L2 Early and Late Age of Acquisition in Experiment 1

\begin{tabular}{lllllllll}
\hline & \multicolumn{3}{l}{ Early Age of Acquisition } & \multicolumn{5}{l}{ Late Age of Acquisition } \\
& Word & & Picture & & Word & Picture & \\
& Rt & Acc. & Rt & Acc. & Rt & Acc. & Rt & Acc. \\
\hline Unrelated & 908 & 2,2 & 974 & 1,1 & 1122 & 1,7 & 1236 & 1,3 \\
Related & 931 & 1,6 & 950 & 1,5 & 1141 & 1,9 & 1206 & 1,4 \\
Sre & -23 & & 24 & & -29 & & 30 & \\
\hline
\end{tabular}

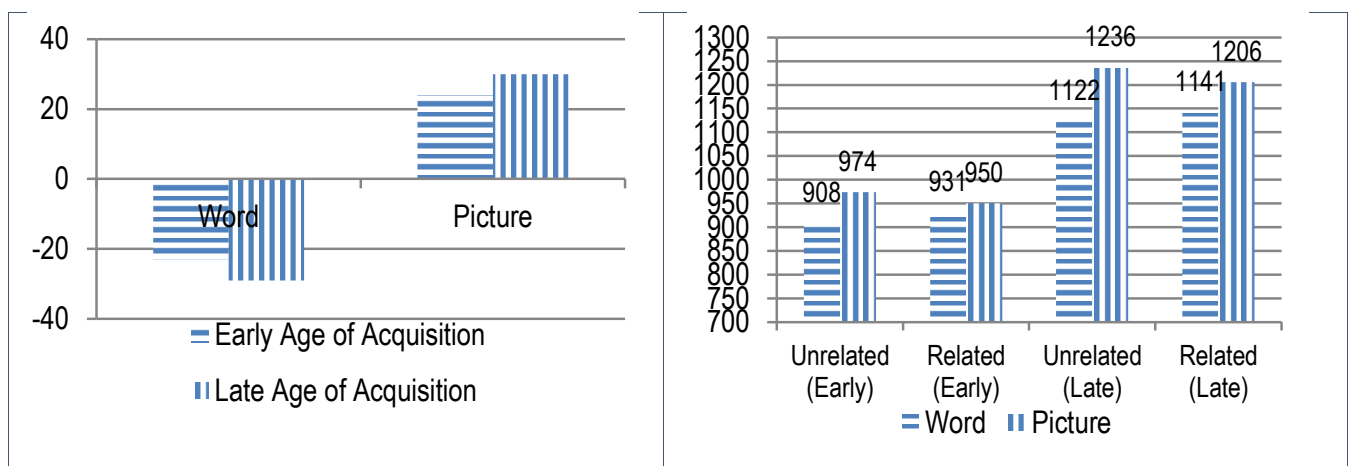

Figure 6. SRE and RTs (in ms. ) for L2 Early and Late Age of Acquisition in Experiment 1

The significant interactions gathered from paired samples statistics in Table 10 and 11 are in Pair 1 as word and picture and Pair 2 as related and unrelated context. First of all, for both groups, on the basis of context there was a significant main effect for bilinguals in early $(t(43)=-2,169, p=0,026, r=0,769)$ and late age of acquisition $(t(63)=-5,173, p=0,000$, $r=0,785)$. Similarly, in terms of relatedness, there was not any significant main effect between those in early age of acquisition ( $t(43)=-0,016 p=0,987, r=0,767)$ and late age of acquisition ( $t(63)=-0,368, p=0,714, r=0,855)$. Consequently, lexical selection and competition occur at conceptual level without inhibition of nontarget language.

Table 10. Paired Samples Statistics for Early Age of Acquisition in L2 in Experiment 1

\section{Paired Samples Statistics}

\section{Paired Samples Correlation}

\begin{tabular}{|c|c|c|c|c|c|c|}
\hline & & Mean & $\mathbf{N}$ & Std. Deviation & Correlation & Sig. \\
\hline Pair 1 & Word & 919,355 & 44 & 1403,000 & 0,769 & 0,000 \\
\hline
\end{tabular}




\begin{tabular}{lllllll}
\hline & Picture & 962,105 & 44 & 1364,651 & & \\
\hline \multirow{2}{*}{ Pair 2 } & Related & 941,613 & 44 & 1367,907 & 0,767 & 0,000 \\
& Unrelated & 940,847 & 44 & 1417,000 & & \\
\hline
\end{tabular}

Paired Samples T-test

\section{PairedDifferences}

\begin{tabular}{lllllll} 
& & Mean & Std. Deviation & $\mathbf{t}$ & $\mathrm{df}$ & Sig. (2-tailed) \\
\hline Pair 1 & Word - Picture & $-3075,010$ & 940,274 & $-2,169$ & 43 & 0,026 \\
\hline Pair 2 & Related - Unrelated & $-2340,450$ & 951,095 & $-0,016$ & 43 & 0,987 \\
\hline
\end{tabular}

Table 11. Paired Samples Statistics for Late Age of Acquisition in L2 in Experiment 1

\begin{tabular}{lllllll}
\hline Paired Samples Statistics & & & & & \\
\hline & & Mean & N & Std. Deviation & Correlation & Sig. \\
\hline \multirow{2}{*}{ Pair 1 } & Word & 1131,121 & 64 & 1830,234 & 0,785 & 0,000 \\
& Picture & 1220,343 & 64 & 2230,126 & & 0,000 \\
\hline \multirow{2}{*}{ Pair 2 } & Related & 1173,324 & 64 & 2120,542 & 0,855 & \\
& Unrelated & 1178,450 & 64 & 2050,409 & &
\end{tabular}

\section{Paired Samples T-test}

\section{Paired Differences}

\begin{tabular}{lllllll} 
& & Mean & $\begin{array}{l}\text { Std. } \\
\text { Deviation }\end{array}$ & $\mathbf{t}$ & df & Sig. (2-tailed) \\
\hline Pair 1 & Word -Picture & $-895,092$ & 1387,876 & $-5,173$ & 63 & 0,000 \\
\hline Pair 2 & Related-Unrelated & $-518,403$ & 1136,435 & $-0,368$ & 63 & 0,714 \\
\hline
\end{tabular}

\section{4. 4 Multilingualism Factor and Lexical Access}

To test the effect of the languages which known by participants except from English, the data obtained from the questionnaire was analyzed and the participants were grouped into two, bilinguals ( $\mathrm{N}=31$ ) and multilinguals $(\mathrm{N}=23)$. As described before, some English learners of Italian know and use French or Spanish ( $N=11)$, while some English learners Turkish know and use German or Arabic $(\mathrm{N}=12)$. Probably surprising fact is that bilinguals were slower than multilinguals in overall translation, context or relatedness. In can be immediately seen in Table 12 that multilinguals' RTs are so closer in context or relatedness; however, bilinguals had some difficulties in translation as expected in CSM hypothesis. Furthermore, multilinguals' SRE in word context (+2) is in positive way like picture context (+30) but different from bilinguals' SRE in word context (-44) (see Figure 7). Only analyzing these results one can say that multilinguals and bilinguals select the language at different levels. However, to get the objective results, independent and paired statistics should be analyzed. 
Independent samples test results show that there is a significant main effect between the groups in the meaning of word ( $t$ $(106)=0,322, p=0,000)$, picture $(t(106)=0,261, p=0,000)$, related $(t(106)=0,472, p=0,000)$ and unrelated context $(t(106)$ $=0,103, p=0,000$ ). That shows that the RTs difference between the groups of bilinguals and multilinguals is meaningful; in other words bilinguals translated the target words in each position slower than multilinguals.

Table 12. Mean RTs (ms. ), Accuracy (in percent) and SRE for Multilinguals and Bilinguals in Experiment 1

\begin{tabular}{lllllllll}
\hline & \multicolumn{3}{l}{ Multilinguals } & \multicolumn{9}{l}{ Bilinguals } \\
& Word & \multicolumn{3}{l}{ Picture } & Word & \multicolumn{3}{c}{ Picture } \\
& Rt & Acc. & Rt & Acc. & Rt & Acc. & Rt & Acc. \\
\hline Unrelated & 902 & 1,1 & 912 & 0,9 & 1128 & 1,3 & 1298 & 2,1 \\
Related & 900 & 1 & 882 & 0,7 & 1172 & 1,7 & 1274 & 1,6 \\
Sre & 2 & & 30 & & -44 & & 24 & \\
\hline
\end{tabular}
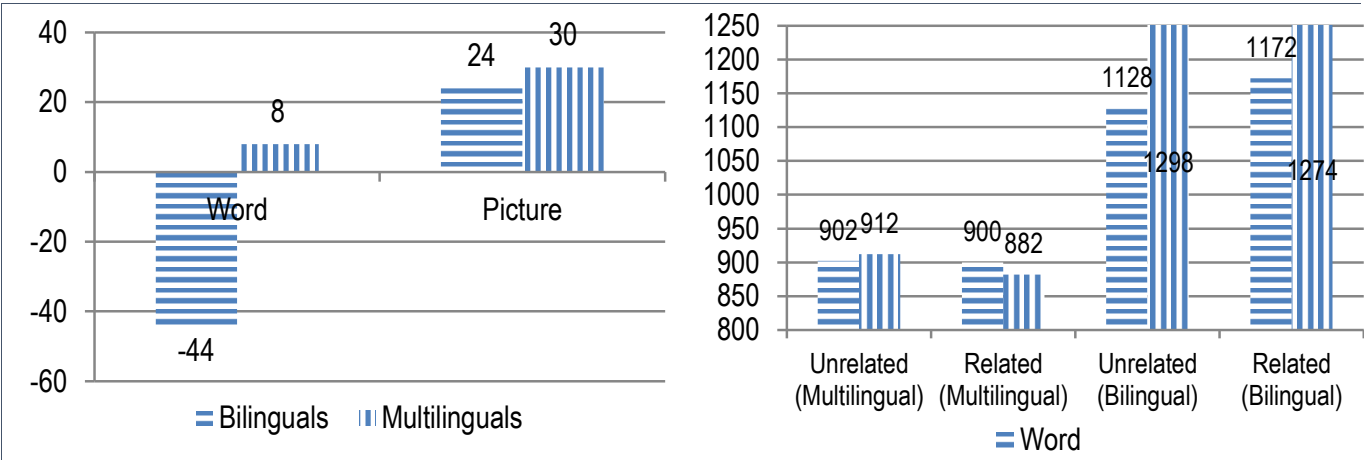

Figure 7. SRE and RTs (in ms) for Multilinguals and Bilinguals in Experiment 1

To analyze the main overall effect of multilingualism on language selection, bilinguals (in Table 13) and multilinguals (in Table 14) were divided into two groups and examined separately. Bilinguals support language selectivity in that locus of selection is at conceptual level since they have the similar results of CSM hypothesis explained at the beginning of the experiment for context $(t(61)=-1,946, p=0,004, r=0,708)$ and relatedness $(t(61)=0,223, p=0,824, r=0,710)$. However, multilinguals statistics result shows that they are probably affected differently in lexical selection such as inhibition or suppression. Moreover, language production can be easier but the lexical selection process can be more difficult. As in the results, significant main effect in context $(t(45)=-2,464, p=0,795, r=0,518)$ and relatedness $(t(45)=-2,377, p=0,743$, $r=0,548$ ) in multilinguals' responses have nothing in common with CSM results.

Table 13. Paired Samples Statistics for Bilinguals in Experiment 1

\section{Paired Samples Statistics}

Paired Samples Correlation

$\begin{array}{llll}\text { Mean } & \mathrm{N} & \text { Std. Deviation } & \\ & \text { Correlation Sig. }\end{array}$




\begin{tabular}{lllllll}
\hline \multirow{2}{*}{ Pair 1 } & Word & 1150,286 & 62 & 2379,291 & 0,708 & 0,000 \\
& Picture & 1286,042 & 62 & 2360,025 & & \\
\hline \multirow{2}{*}{ Pair 2 } & Related & 1223,233 & 62 & 2393,479 & 0,710 & 0,000 \\
& Unrelated & 1213,095 & 62 & 2366,952 & & \\
\hline
\end{tabular}

Paired Samples T-test

Paired Differences

\begin{tabular}{|c|c|c|c|c|c|c|}
\hline & & Mean & Std. Deviation & $\mathrm{t}$ & df & Sig. (2-tailed) \\
\hline Pair 1 & Word - Picture & $-4475,660$ & 1810,837 & $-1,946$ & 61 & 0,004 \\
\hline Pair 2 & Related - Unrelated & 5137,435 & 1812,483 & 0,223 & 61 & 0,824 \\
\hline
\end{tabular}

Table 14. Paired Samples Statistics for Multilinguals in Experiment 1

\begin{tabular}{|c|c|c|c|c|c|c|}
\hline \multicolumn{7}{|c|}{ Paired Samples T-test Statistics } \\
\hline & & \multirow[b]{2}{*}{ Mean } & \multirow[b]{2}{*}{$\mathbf{N}$} & \multirow[b]{2}{*}{$\begin{array}{l}\text { Std. } \\
\text { Deviation }\end{array}$} & \multicolumn{2}{|c|}{ Paired Samples Correlation } \\
\hline & & & & & Correlation & Sig. \\
\hline \multirow{2}{*}{ Pair 1} & Word & 901,364 & 46 & 1884,248 & 0,518 & 0,000 \\
\hline & Picture & 897,683 & 46 & 2530,586 & & \\
\hline \multirow{2}{*}{ Pair 2} & Related & 891,365 & 46 & 2034,730 & 0,548 & 0,000 \\
\hline & Unrelated & 907,378 & 46 & 2314,564 & & \\
\hline
\end{tabular}

\section{Paired Samples T-test}

\begin{tabular}{llllllll}
\hline & & \multicolumn{2}{c}{ Paired Differences } & & \\
& & Mean & Std. Deviation & $\mathbf{t}$ & df & Sig. (2-tailed) \\
\hline Pair 1 & Word - Picture & $-813,192$ & 2238,712 & $-2,464$ & 45 & 0,795 \\
\hline Pair 2 & Related - Unrelated & $-730,130$ & 2083,130 & $-2,377$ & 45 & 0,743 \\
\hline
\end{tabular}

\section{Expriment 2: Numeral Task}

\section{1 Materials}

Participants switched between their dominant language Italian or Turkish (L1) and English (L2). Numbers (from 0 to 9) were presented unpredictably. They chose the language of the response according to the color of the background (blue or yellow). All of the participants were instructed that "blue" indicated "respond in English" and "yellow" indicated "respond in Turkish or Italian". As in Costa \& Santesteban (2004), there were two types of trials in which the language of response (either in L1 or L2) was either the same as the trial immediately before (nonswitch trial) or different than that used in the preceding trial (switch trials). These responses were produced in both L1 and L2 and there were four different types of 
trials: switch to $L 1$, switch to $L 2$, nonswitch in $L 1$, nonswitch in $L 2$. The total number of the trials in the experiment was 1000 (700 nonswitch trials $(70 \%)$ and 300 switch trials $(30 \%)$. There was the same number of production in L1 or L2 (500 responses for each language). Each number was presented 100 times during the experiment.

\section{2 Procedure}

The participants were tested individually in a soundproof room immediately after Experiment 1 . As in the first experiment, in written and orally, they were asked to name the digits which were seen on the computer screen according to the background color of them. When the digits were seen in blue color they were expected to answer in L2, in yellow color they were expected to answer in L1. Each participant was given the numbers in a series of 100 digits. Each number appeared on the computer screen and remained for $800 \mathrm{~ms}$. If the participant does not give any answer during this time, the next trial was seen on the screen and this procedure repeated until the end of the list, at which time an asterisk $\left(^{*}\right)$ was presented for $1000 \mathrm{~ms}$ to show that the list finished and another one would begin in $1000 \mathrm{~ms}$. After each 10 lists, participants were given a break of approximately 5 minutes to prevent participants from overloading. All responses were recorded as in the first experiment and coded as "correct" or "incorrect".

\section{3 Data Analysis}

Response latencies of only correct responses (in L1 or L2) were included in the statistical analyses. There are two main variables as L1-L2 or switch-nonswitch contexts. The analyses were conducted to each bilingual group separately as mentioned in Experiment 1.

\section{4 Results and Discussion}

Numeral task including language switches was conducted to observe whether lexical access and language selection occur at lexical level or not. Recall that IC model hypothesize the words in the nontarget language are inhibited to produce of the target language because there is difference in the size of $L 1$ and $L 2$, in other words $L 1$ system is larger than $L 2$ system so $\mathrm{L} 1$ must be reactivated. That is the reason why more time is needed when switching into larger one of two systems. Previous researchers (Costa \& Santesteban, 2004; Meuter, 1994; Meuter \& Allport, 1999) claimed that asymmetric switch cost (ASC) is associated with L1 and L2 switches and in the present experiment RTs of language (L1 and L2) and trial type (switch and nonswitch) performances were analyzed separately. This experiment is also important to understand the factors which have been consisted in CSM and Word Translation Task to see the main effect of this difference between participants in terms of $L 2$ proficiency level and multilingualism. As in Table 15, the RTs results show that regardless of the factors, all bilinguals were slower in naming the switch trials than nonswitch trials. Also, they were slower in naming $L 1$ trials than $L 2$ trials. Furthermore there was a significant effect for response language ( $L 1$ and $L 2)(t(107)=6,801, p=0,000, r=0,697)$ and trial type (switch and nonswitch) $(t(107)=7,943, p=0,000, r=0,743$ ). It can be understood from the statistics that switching to L1 is more difficult than switching to L2 and ASC for switch trials is more than nonswitch trials.

Table 15. Paired Samples Statistics for Language Response (L1 or L2) and Trial Types (switch-nonswitch) in Experiment 2

\section{Paired Samples Statistics}

Paired Samples Correlation

\begin{tabular}{lllllll} 
& & Mean & N & Std. Deviation & Correlation & Sig. \\
\hline \multirow{2}{*}{ Pair 1 } & L1 & 659,422 & 108 & 1271,646 & 0,697 & 0,000 \\
& L2 & 597,942 & 108 & 1109,985 & & \\
\hline
\end{tabular}




\begin{tabular}{|c|c|c|c|c|c|c|}
\hline \multirow{2}{*}{ Pair 2} & Switch & 661,959 & 108 & 1288,924 & \multirow[t]{2}{*}{0,743} & \multirow[t]{2}{*}{0,000} \\
\hline & Nonswitch & 595,405 & 108 & 1074,728 & & \\
\hline
\end{tabular}

\section{Paired Differences}

\begin{tabular}{lllllll} 
& & Mean & Std. Deviation & $\mathbf{t}$ & df & Sig. (2-tailed) \\
\cline { 2 - 6 } Pair 1 & L1 - L2 & 61480,18 & 93945,09 & 6,801 & 107 & 0,000 \\
\hline Pair 2 & Switch - Nonswitch & 66553,92 & 87079,64 & 7,943 & 107 & 0,000 \\
\hline
\end{tabular}

\section{4. 1 L1 Factor and Lexical Access}

One of the main aims of this experiment is to see whether $\mathrm{L} 1$ factor affects the locus of language selection and completion during bilingual speech production. To analyze this factor, participants are grouped into two; English learners of Italian and English learners of Turkish. The mean reaction times gathered from the experiment show that switch trials take longer than nonswitch trials and Italian participants' RTs are more than Turkish participants' (see Table 16 and for graph see Figure 8).

In language response and trial type observation, there is a significant main effect between L1 Turkish and Italian participants. According to the independent samples test results, there is a significant main effect between two groups on the basis of $L 1(t(95,8)=-3,929, p=0,000), \mathrm{L} 2(t(106)=-2,643, p=0,009)$, switch $(t(96,416)=-3,383, p=0,001)$ and nonswitch $(t(106)=-3,294, p=0,001)$ trials.

Table 16. Mean RTS (ms. ), Accuracy (in percent) and ASC for L2 learners of Italian and Turkish in Experiment 2

\section{L1 Italian}

\section{L1 Turkish}

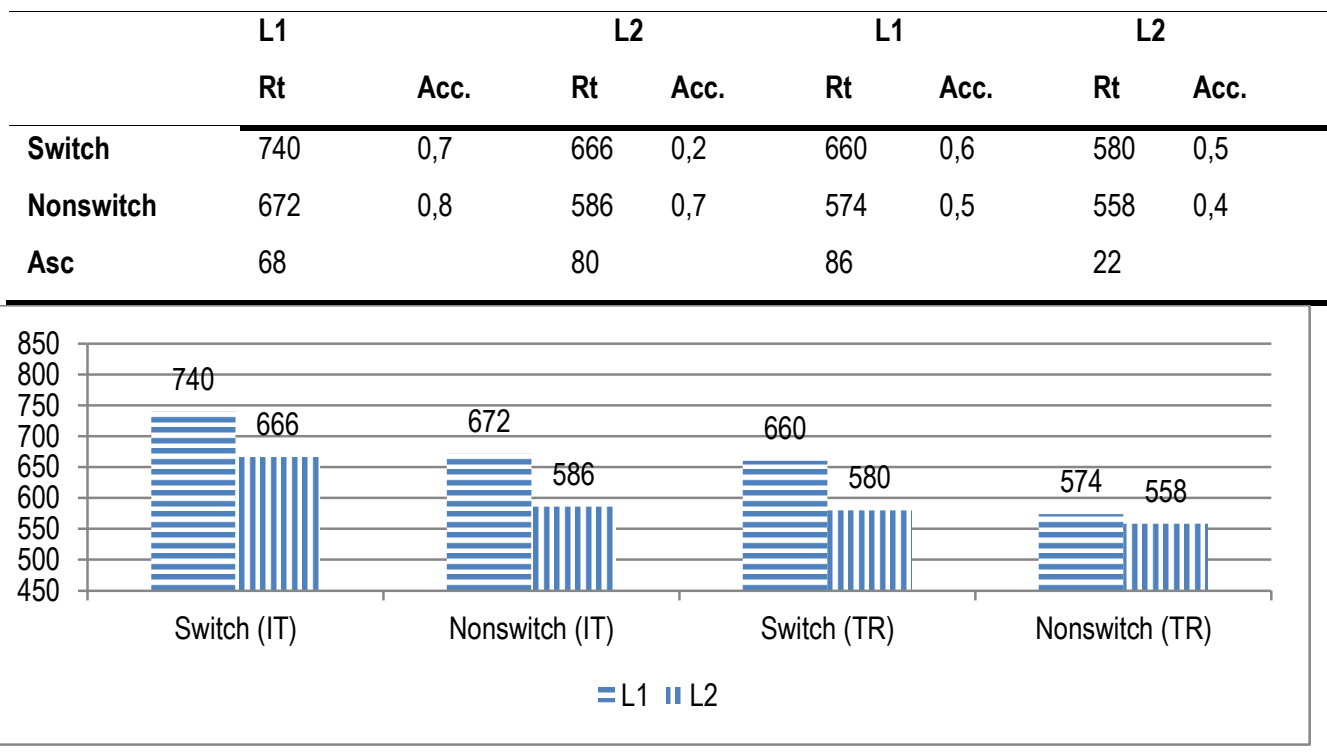

Figure 8. RTs (in ms. ) for L2 learners of Italian and Turkish in Experiment 2 
To analyze the main effect of the switch or nonswitch trials, L1 Turkish and L1 Italian participants are examined separately with paired samples statistics (as in Table 17 and 18). The language response and trial type data are obtained from each group and the RTs show that the results of both group are similar to each other in terms of "language response" for L1 Turkish ( $t(55)=4,279, p=0,000, r=0,742)$ and $\mathrm{L} 1$ Italian $(t(51)=5,413, p=0,000, r=0,626)$. Similarly, the "trial type responses" are similar to each other because there is a significant main effect between switch and nonswitch trials for L1 Turkish $(t(55)=6,681, p=0,000, r=0,803)$ and $L 1$ Italian $(t(51)=5,117 p=0,000, r=0,652)$ groups. Consequently, similar effects can be seen for both groups and the results support ICM regardless of what type of bilingual one may be. That is, locus of language selection and lexical access process are solved at lexical level as long as language switching is needed in production of target language.

Table 17. Paired Samples Statistics for L2 Learners of Turkish in Experiment 2

\begin{tabular}{|c|c|c|c|c|c|c|}
\hline \multicolumn{7}{|c|}{ Paired Samples Statistics } \\
\hline & & \multirow[b]{2}{*}{ Mean } & \multirow[b]{2}{*}{$\mathbf{N}$} & \multirow[b]{2}{*}{$\begin{array}{l}\text { Std. } \\
\text { Deviation }\end{array}$} & \multicolumn{2}{|c|}{ Paired Samples Correlation } \\
\hline & & & & & Correlation & Sig. \\
\hline \multirow{2}{*}{ Pair 1} & L1 & 617,575 & 56 & 1034,706 & 0,742 & 0,000 \\
\hline & L2 & 569,466 & 56 & 1104,983 & & \\
\hline \multirow{2}{*}{ Pair 2} & Switch & 620,046 & 56 & 1074,538 & 0,803 & 0,000 \\
\hline & Nonswitch & 566,995 & 56 & 1028,838 & & \\
\hline
\end{tabular}

\section{Paired Samples $T$-test}

\section{Paired Differences}

\begin{tabular}{lllllll} 
& & Mean & Std. Deviation & $\mathbf{t}$ & df & Sig. (2-tailed) \\
\hline Pair 1 & L1 - L2 & 44109,52 & 77141,57 & 4,279 & 55 & 0,000 \\
\hline Pair 2 & Switch - Nonswitch & 59050,02 & 66139,71 & 6,681 & 55 & 0,000 \\
\hline
\end{tabular}

Table 18. Paired Samples Statistics for L2 learners of Italian in Experiment 2

\begin{tabular}{|c|c|c|c|c|c|c|}
\hline \multicolumn{7}{|c|}{ Paired Samples Statistics } \\
\hline \multirow[t]{2}{*}{ it } & & \multirow[b]{2}{*}{ Mean } & \multirow[b]{2}{*}{$\mathbf{N}$} & \multirow[b]{2}{*}{$\begin{array}{l}\text { Std. } \\
\text { Deviation }\end{array}$} & \multicolumn{2}{|c|}{ Paired Samples Correlation } \\
\hline & & & & & Correlation & Sig. \\
\hline \multirow{2}{*}{ Pair 1} & L1 & 706,641 & 52 & 1341,522 & 0,626 & 0,000 \\
\hline & L2 & 626,454 & 52 & 1052,766 & & \\
\hline \multirow{2}{*}{ Pair 2} & Switch & 703,865 & 52 & 1376,593 & 0,652 & 0,000 \\
\hline & Nonswitch & 629,230 & 52 & 1028,013 & & \\
\hline
\end{tabular}

\section{Paired Samples $T$-test}




\begin{tabular}{lllllll}
\hline & \multicolumn{2}{c}{ Paired Differences } & & \\
& & Mean & Std. Deviation & $\mathbf{t}$ & df & Sig. (2-tailed) \\
\hline Pair 1 & L1 - L2 & 801,870 & 1068,220 & 5,413 & 51 & 0,000 \\
\hline Pair 2 & Switch - Nonswitch & 746,350 & 1051,816 & 5,117 & 51 & 0,000 \\
\hline
\end{tabular}

\section{4. 2 L2 Proficiency Level Factor and Lexical Access}

As in the first experiment, the participants were categorized into two according to L2 proficiency level; low and highly proficient bilinguals. As expected, mean reaction times show highly proficient bilinguals are faster than low proficient ones. However, as Table 19 illustrates, ASC in L1 and L2 for low proficient bilinguals (117 ms. , $64 \mathrm{~ms}$. respectively) is much more than highly proficient bilinguals' cost (47 ms. , $38 \mathrm{~ms}$. ) (Figure 9 shows more detailed graph). These findings are important because they do not validate the hypotheses of ICM and support the findings found in Experiment 1 . From these results, it can be assumed that in order to select the appropriate word in the target language, low proficient bilinguals must inhibit the nonrelevant language temporarily.

According to the independent samples test, there is a significant main effect between two groups in terms of $L 1(t(95,8)$ $=6,484, p=0,000)$, L2 ( $t(106)=6,863, p=0,000)$, switch $(t(106)=7,222, p=0,000)$ and nonswitch trials $(t(106)=6,181$, $p=0,000)$. Analyzing these results it can be assumed that low proficient bilinguals are slower than highly proficient bilinguals as expected. However, to get knowledge about what the main difference between them, separate analyses with paired samples test are needed.

Table 19. Mean RTs (ms. ), Accuracy (in percent) and ASC for L2 Low and Highly Proficient Bilinguals in Experiment 2

\begin{tabular}{|c|c|c|c|c|c|c|c|c|}
\hline & \multicolumn{4}{|c|}{ L2 Low Proficiency } & \multicolumn{4}{|c|}{ L2 High Proficiency } \\
\hline & \multicolumn{2}{|c|}{ L1 } & \multicolumn{2}{|c|}{ L2 } & \multicolumn{2}{|c|}{ L1 } & \multicolumn{2}{|c|}{ L2 } \\
\hline & Rt & Acc. & Rt & Acc. & Rt & Acc. & $\mathrm{Rt}$ & Acc. \\
\hline Switch & 796 & 0,8 & 696 & 0,3 & 604 & 0,6 & 550 & 0,4 \\
\hline Nonswitch & 679 & 0,7 & 632 & 0,7 & 557 & 0,6 & 512 & 0,4 \\
\hline Asc & 117 & & 64 & & 47 & & 38 & \\
\hline
\end{tabular}

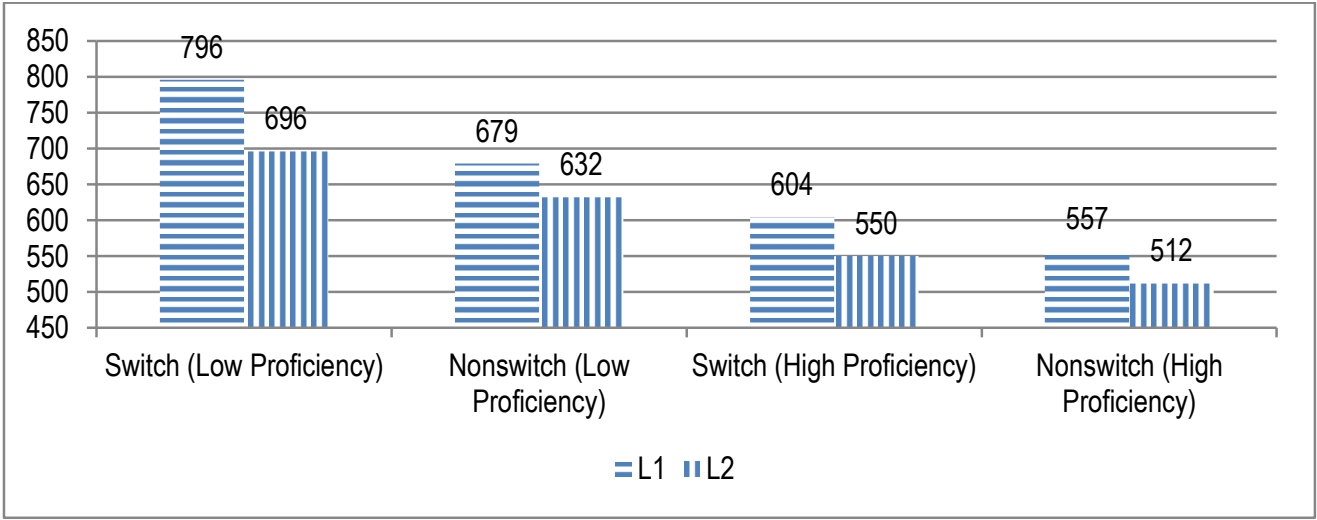


Figure 9. RTs (in ms. ) for L2 Low and Highly Proficient Bilinguals in Experiment 2

Paired samples statistics are shown in Table 20 and 21 separately. They are analyzed for the same reason in the first experiment and there are several significant interactions in the results. Most importantly, for language response and trial types, only low proficient bilinguals could get the significant effect for language response $(t(53)=4,595, p=0,000, r=0,526)$ and for trial types $(t(53)=4,541, p=0,000, r=0,611)$. These results are also parallel to the results of ICM itself (Green, 1998) which has been found at the beginning of the study. Alike low proficient bilinguals, highly proficient bilinguals could not get the significant effect for both language response $(t(53)=1,862, p=0,068, r=0,831)$ and trial types $(t(53)=2,159$, $p=0,064, r=0,721)$. The results of the present experiment for low proficient bilinguals are completely in line with the claims put forth by ICM and the inhibition rules to produce target language. On the other hand, the same discussion is not possible for highly proficient bilinguals in the shadow of their asymmetric switch cost; in other words, highly proficient bilinguals are completely in line with CSM and they select language at conceptual level using language cues in preverbal message.

Table 20. Paired Samples Statistics for L2 Low Proficient Bilinguals in Experiment 2

\begin{tabular}{|c|c|c|c|c|c|c|}
\hline \multicolumn{7}{|c|}{ Paired Samples Statistics } \\
\hline & & \multirow[b]{2}{*}{ Mean } & \multirow[b]{2}{*}{$\mathbf{N}$} & \multirow[b]{2}{*}{$\begin{array}{l}\text { Std. } \\
\text { Deviation }\end{array}$} & \multicolumn{2}{|c|}{ Paired Samples Correlatior } \\
\hline & & & & & Correlation & Sig. \\
\hline \multirow{2}{*}{ Pair 1} & L1 & 737,876 & 54 & 1193,714 & 0,526 & 0,000 \\
\hline & L2 & 664,222 & 54 & 1000,946 & & \\
\hline \multirow{2}{*}{ Pair 2} & Switch & 746,632 & 54 & 1165,801 & 0,611 & 0,000 \\
\hline & Nonswitch & 655,466 & 54 & 965,099 & & \\
\hline
\end{tabular}

\section{Paired Samples T-test}

\section{Paired Differences}

\begin{tabular}{lllllll} 
& & Mean & $\begin{array}{l}\text { Std. } \\
\text { Deviation }\end{array}$ & $\mathbf{t}$ & df & Sig. (2-tailed) \\
\hline Pair 1 & L1 - L2 & 676,537 & 1082,010 & 4,595 & 53 & 0,000 \\
\hline Pair 2 & Switch - Nonswitch & 851,661 & 956,835 & 6,541 & 53 & 0,000 \\
\hline
\end{tabular}

Table 21. Paired Samples Statistics for L2 Highly Proficient Bilinguals in Experiment 2

\section{Paired Samples Statistics}

\begin{tabular}{|c|c|c|c|c|c|c|}
\hline & & & & & Paired Samr & Correlation \\
\hline & & Mean & $\mathbf{N}$ & $\begin{array}{l}\text { Std. } \\
\text { Deviation }\end{array}$ & Correlation & Sig. \\
\hline & L1 & 580,968 & 54 & 955,273 & 0,831 & 0,000 \\
\hline (11 & L2 & 531,402 & 54 & 1014,424 & & \\
\hline Pair 2 & Switch & 577,285 & 54 & 942,799 & 0,721 & 0,000 \\
\hline
\end{tabular}




$\begin{array}{llll}\text { Nonswitch } & 534,121 & 54 & 888,809\end{array}$

\section{Paired Samples T-test}

\begin{tabular}{lllllll}
\hline & & \multicolumn{2}{l}{ Paired Differences } & & \\
& & Mean & Std. Deviation & $\mathbf{t}$ & df & Sig. (2-tailed) \\
\hline Pair 1 & L1 - L2 & 1456,587 & 574,961 & 1,862 & 53 & 0,068 \\
\hline Pair 2 & Switch - Nonswitch & 2016,394 & 686,457 & 2,159 & 53 & 0,064 \\
\hline
\end{tabular}

\section{4. 3 L2 Age of Acquisition Factor and Lexical Access}

As was emphasized in L2 Age of Acquisition Factor and Language Selection section of Experiment 1, all participants were grouped into two, L2 early and late age of acquisition. As expected, those in early age of acquisition were faster than those in late age of acquisition. However, as shown in Table 22, their ASC rate is similar to each other, as for L1: $82 \mathrm{~ms}$. to $83 \mathrm{~ms}$. (early and late age of acquisition respectively) and for L2: $48 \mathrm{~ms}$. to $53 \mathrm{~ms}$. (also see Figure 10). From these results, it is obvious to predict that all bilinguals regardless of their L2 age of acquisition proceeds their lexical selection via ICM hypothesis. In other words, they use inhibitory control mechanisms in selection target language as long as they do language switching.

Age of acquisition independent samples analyses also show that there was an overall main effect for $L 1(t(106)=-3,014$, $p=0,003)$, L2 ( $t(106)=-3,404, p=0,001)$, switch $(t(106)=-2,980, p=0,004)$ and nonswitch $(t(106)=-3,516, p=0,001)$ trials. To analyze the main overall effect of language response and trial types, both groups must be indicated separately.

Table 22. Mean RTs (ms. ), Accuracy (in percent) and ASC for L2 Early and Late Age of Acquisition in Experiment 2

\begin{tabular}{llllllllll}
\hline & \multicolumn{3}{l}{ Early Age of Acquisition } & \multicolumn{5}{l}{ Late Age of Acquisition } \\
& L1 & \multicolumn{3}{l}{ L2 } & \multicolumn{2}{c}{ L1 } & \multicolumn{2}{c}{ L2 } \\
& Rt & Acc. & Rt & Acc. & Rt & Acc. & Rt & Acc. \\
\hline Switch & 656 & 0,8 & 578 & 0,1 & 745 & 0,6 & 668 & 0,3 \\
Nonswitch & 574 & 0,8 & 530 & 0,9 & 662 & 0,7 & 615 & 0,4 \\
Asc & 82 & & 48 & & 83 & & 53 & \\
\hline
\end{tabular}




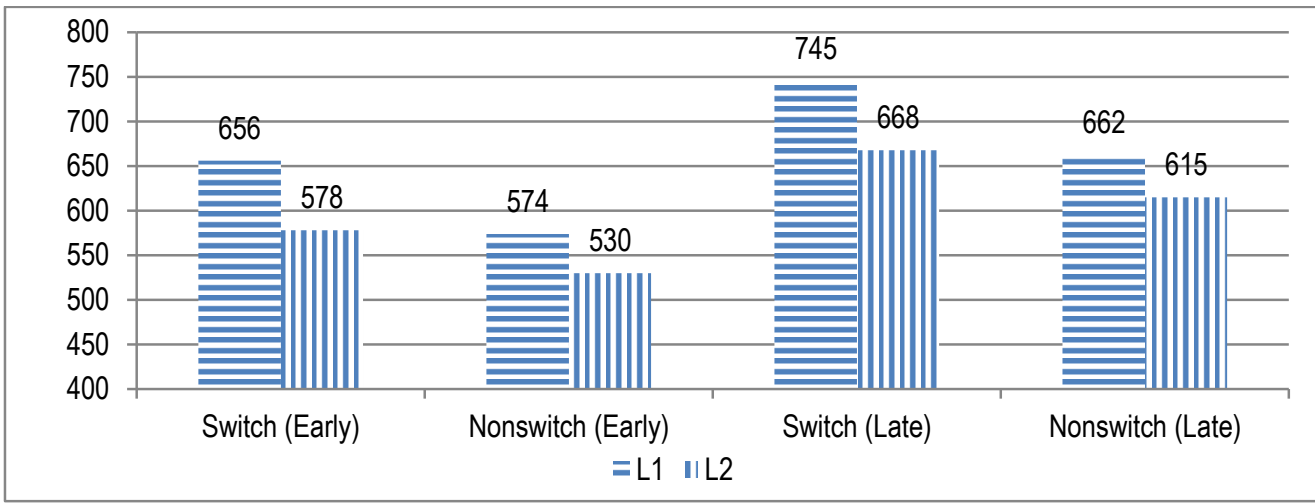

Figure 10. RTs (in ms. ) for L2 Early and Late Age of Acquisition in Experiment 2

The magnitude interactions obtained from paired samples statistics (in Table 23 and 24) are as follows: First, there was an observed main effect in response language for those in not only early age of acquisition ( $t(41)=5,252 p=0,000, r=0,811$ ) but also late age of acquisition ( $t(65)=4,811, p=0,000, r=0,562$ ). Second, the last observed significant main effect can be analyzed from the part of trial types and both the participants who are at early age of acquisition $(t(41)=5,372, p=0,000$, $r=0,799)$ and late age of acquisition $(t(65)=5,914, p=0,000, r=0,657)$ get similar results. The findings from these analyses suggest that $L 2$ age of acquisition does not affect the locus of language selection and competition. Surprisingly, although they are totally different from each other in nature their statistics are similar except from the time they needed to name the digits in target language.

Table 23. Paired Samples Statistics for L2 Early Age of Acquisition in Experiment 2

\section{Paired Samples Statistics}

Paired Samples Correlation

\begin{tabular}{lllllll} 
& & Mean & N & $\begin{array}{l}\text { Std. } \\
\text { Deviation }\end{array}$ & Correlation & Sig. \\
\hline \multirow{2}{*}{ Pair 1 } & L1 & 614,849 & 42 & 1228,812 & 0,811 & 0,000 \\
& L2 & 554,465 & 42 & 1189,993 & \\
\hline \multirow{2}{*}{ Pair 2 } & SWITCH & 617,251 & 42 & 1303,556 & 0,799 & 0,000 \\
& NONSWiTCH & 552,063 & 42 & 1093,575 & & \\
\hline
\end{tabular}

\section{Paired Samples T-test}

\section{Paired Differences}

\begin{tabular}{lllllll} 
& & Mean & $\begin{array}{l}\text { Std. } \\
\text { Deviation }\end{array}$ & $\mathbf{t}$ & df & $\begin{array}{l}\text { Sig. } \\
\text { tailed) }\end{array}$ \\
\hline Pair 1 & L1 - L2 & 603,843 & 745,157 & 5,252 & 41 & 0,000 \\
\hline Pair 2 & Switch - Nonswitch & 651,882 & 786,445 & 5,372 & 41 & 0,000 \\
\hline
\end{tabular}


Table 24. Paired Samples Statistics for L2 Late Age of Acquisition in Experiment 2

\section{Paired Samples Statistics}

Paired Samples Correlation

\begin{tabular}{lllllll} 
& & Mean & N & $\begin{array}{l}\text { Std. } \\
\text { Deviation }\end{array}$ & Correlation & Sig. \\
\hline \multirow{2}{*}{ Pair 1 } & L1 & 703,786 & 66 & 1224,523 & 0,562 & 0,000 \\
& L2 & 641,609 & 66 & 966,999 & & \\
\hline \multirow{2}{*}{ Pair 2 } & Switch & 706,409 & 66 & 1204,832 & 0,657 & 0,000 \\
& Nonswitch & 638,986 & 66 & 973,863 & & \\
\hline
\end{tabular}

\section{Paired Samples T-test}

\begin{tabular}{lllllll}
\hline & & \multicolumn{2}{l}{ Paired Differences } & & \\
& & Mean & Std. Deviation & t & df & Sig. (2-tailed) \\
\hline Pair 1 & L1 - L2 & 621,775 & 1049,988 & 4,811 & 65 & 0,000 \\
\hline Pair 2 & Switch - Nonswitch & 674,229 & 926,245 & 5,914 & 65 & 0,000 \\
\hline
\end{tabular}

\section{4. 4 Multilingualism Factor and Lexical Access}

In the light of diverse language histories and background, the participants who knew and used other languages except from English were separated from those who knew and used only English as L2 as explained in Experiment 1. Alike word translation task, the multilinguals were slower in naming digits than bilinguals in numeral task. Moreover, as Table 25 illustrates asymmetric switch cost shows that multilinguals needed more time ( $A S C=115 \mathrm{~ms}$.) switching from $L 2$ to $L 1$ than bilinguals needed (ASC. $=49 \mathrm{~ms}$.). The same effect can be seen in L2 asymmetric switch cost (also see Figure 11). The analyses present the effects of certain factors on the nature of multilinguals such as inhibition effect of the other language (L3). To be sure on this hypothesis, it will be suggested to obtain data from two groups first comparatively and then separately. Independent samples test results suggest that there is a significant main effect between participants in terms of L1 ( $t(106)=-3,481, p=0,001)$, L2 ( $t(106)=-5,228, p=0,000)$, switch $(t(106)=-4,214, p=0,000)$ and nonswitch $(t(106)=-$ $4,391, p=0,000)$ trials. That shows that bilinguals are faster in naming digits than multilinguals.

Table 25. Mean RTs (ms. ), Accuracy (in percent) and ASC for Multilinguals and Bilinguals in Experiment 2

\begin{tabular}{lllllllll}
\hline & \multicolumn{7}{l}{ Multilinguals } & \multicolumn{7}{l}{ Bilinguals } \\
& L1 & & L2 & & L1 & L2 & \\
& Rt & Acc. & Rt & Acc. & Rt & Acc. & Rt & Acc. \\
\hline Switch & 777 & 0,3 & 677 & 0,4 & 623 & 0,5 & 569 & 0,5 \\
Nonswitch & 662 & 0,6 & 610 & 0,2 & 574 & 0,7 & 534 & 0,4
\end{tabular}


Asc

115

67

49

35

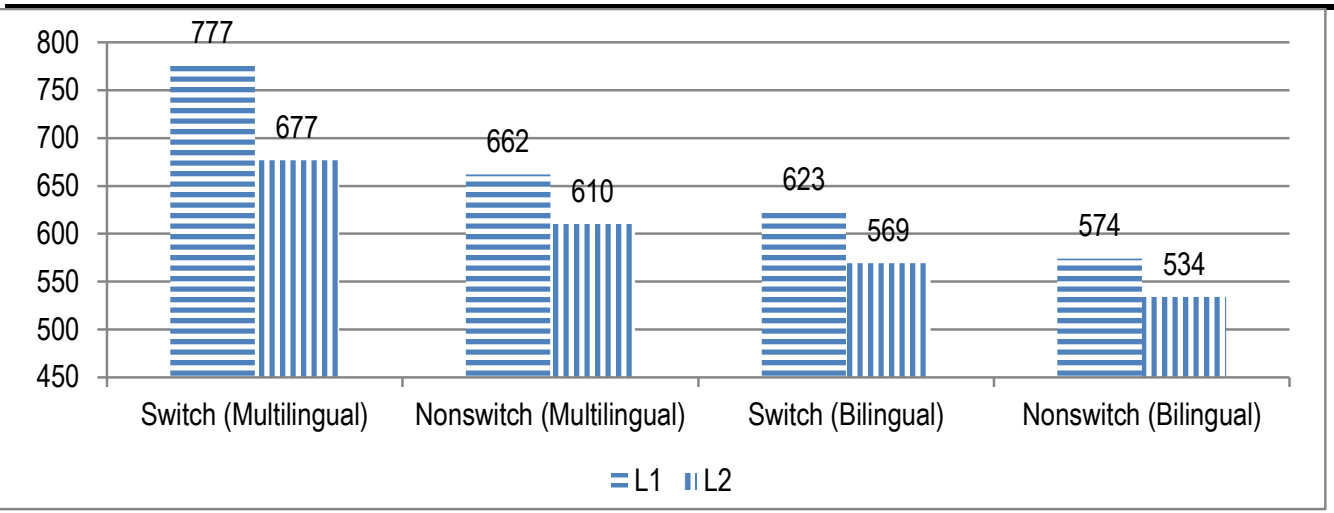

Figure 11. RTs (in ms) for Multilinguals and Bilinguals in Experiment 2

Main overall effect of multilingualism in language selection and lexical access process should be considered as significant. Since, only indicating the RTs and ASCs, one may predict, multilinguals are affected from different process during the language selection. Also, one may ask why multilinguals had difficulty in naming digits instead of being fast because of the proficiency levels. The answer to this question is coming from IC model; because the inhibitory control mechanisms prevent them producing the language at conceptual level but lexical level and that is the reason why switching from $L 2$ to $L 1$ is more difficult than L1 to L2 when they are compared with bilinguals. The paired samples results shown in Table 26 and 27 say that there is a significant main effect in language response $(t(45)=1,973, p=0,021, r=0,737)$ and trial types $(t(45)=2,391$, $p=0,015, r=0,476)$ in multinguals' responses. However, we cannot see the significant main effect in bilinguals language responses $(t(61)=6,032, p=0,065, r=0,637$ and trial types $(t(61)=5,860, p=0,074, r=0,705)$. Finally, these analyses suggest that multilinguals use inhibitory control during lexical selection and that bilinguals do not.

Table 26. Paired Samples Statistics for Bilinguals in Experiment 2

Paired Samples Correlation

\begin{tabular}{lllllll} 
& & Mean & N & Std. Deviation & Correlation & Sig. \\
\hline \multirow{2}{*}{ Pair 1 } & L1 & 598,501 & 62 & 1163,691 & 0,637 & 0,000 \\
& L2 & 551,852 & 62 & 888,780 & & \\
\hline \multirow{2}{*}{ Pair 2 } & Switch & 596,097 & 62 & 1126,700 & 0,705 & 0,000 \\
& Nonswitch & 554,256 & 62 & 965,950 & &
\end{tabular}

Paired Samples T-test

\section{EşleştirilmişFark}

\begin{tabular}{|c|c|c|c|c|c|}
\hline & & Mean & Std. Deviation & df & Sig. (2-tailed) \\
\hline Pair 1 & L1 - L2 & 696,493 & 909,148 & $6,032 \quad 61$ & 0,065 \\
\hline Pair 2 & Switch - Nonswitch & 608,409 & 817,477 & $5,860 \quad 61$ & 0,074 \\
\hline
\end{tabular}


Table 27. Paired Samples Statistics for Multilinguals in Experiment 2

\begin{tabular}{|c|c|c|c|c|c|c|}
\hline \multicolumn{7}{|c|}{ Paired Samples Statistics } \\
\hline & & \multirow[b]{2}{*}{ Mean } & \multirow[b]{2}{*}{$\mathbf{N}$} & \multirow[b]{2}{*}{ SS } & \multicolumn{2}{|c|}{ Paired Samples Correlation } \\
\hline & & & & & Correlation & Sig. \\
\hline \multirow{2}{*}{ Pair 1} & L1 & 719,227 & 46 & 1192,693 & 0,737 & 0,000 \\
\hline & L2 & 643,845 & 46 & 1106,681 & & \\
\hline \multirow{2}{*}{ Pair 2} & Switch & 727,598 & 46 & 1148,655 & 0,476 & 0,000 \\
\hline & Nonswitch & 636,126 & 46 & 1029,037 & & \\
\hline
\end{tabular}

Paired Samples T-test

\begin{tabular}{lllllll}
\hline \multicolumn{7}{c}{ Paired Differences } \\
& Mean & $\begin{array}{l}\text { Std. } \\
\text { Deviation }\end{array}$ & $\mathbf{t}$ & df & Sig. (2-tailed) \\
\hline Pair 1 & L1 - L2 & 2438,26 & 838,343 & 1,973 & 45 & 0,021 \\
\hline Pair 2 & Switch - Nonswitch & 3947,143 & 1119,628 & 2,391 & 45 & 0,015 \\
\hline
\end{tabular}

\section{Conclusion and Suggestion}

The answer to the question whether basic factors such as L1, L2 proficiency level, L2 age of acquisition and multilingualism affect the locus of language selection and lexical access process is tried to be given in this study. After the analyses, it can be concluded that while more proficient learners provide support for CSM, less proficient learners provide support for ICM for the first experiment. Besides, multilingual speakers provide support for ICM bilingual speakers provide support for CSM for the second experiment. Finally, it can be proposed that language selection and competition differ according to the some basic factors such as L2 proficiency level and multilingualism and these are the determining factor in the locus of language selection during lexical access (Demiray, 2014).

Based on this general conclusion, in figure 12, Language Selection by L2 Proficiency and Multilingualism Model has been proposed. In this model, English learner of Italian is shown the concept "chair" and expected to name it in L1. When target language is produced, if $\mathrm{L} 2$ proficiency level is high, semantic system will immediately activate lexical nodes of target language in preverbal message; however lexical nodes of nontarget language will not be activated. Thus, language selection occurs within target language only using one lexicon without competition for selection across languages. On the other hand, if L2 proficiency level of the participant is low, inhibitory control mechanisms will be involved in language selection. Nontarget language lexicon will compete for selection with target language lexicon at lexical level. In other words, the higher L2 proficiency is, the more language selection occurs at conceptual level. However, if the participant is multilingual, the inhibition occurring at lexical level will be stronger and response time will be longer.

Whatever $L 3$ proficiency level is, the multilingual will go into production of target language at lexical level and lexicons for each language will compete with each other and finally the more highly activated lexicon will be the winner. As in figure 12 , the higher English learner of Italian participant's L2 proficiency level is, the more he/she will shifte to conceptual level from lexical level (follow arrows in figure). If this participant has L3 knowledge, inhibitory control mechanisms get on the stage, lexicons and the lexical nodes regarding L2 (English) and L3 (Spanish) are suppressed and the language production in L1 (Italian) occurs in a higher cost.

The statistical analyses of two experiments questioned whether the findings of previous research (Costa \& Santesteban, 2004; La Heij, 2004; Meuter \& Allport, 1999 and Schwieter, 2007) can be generalized to late bilinguals or multilinguals who 
have different language backgrounds. Finally, it was seen that language selection at conceptual or lexical level differs depending on L2 Proficiency Level (as in Costa \& Santesteban, 2004 and Schwieter, 2007) and Multilingualism.

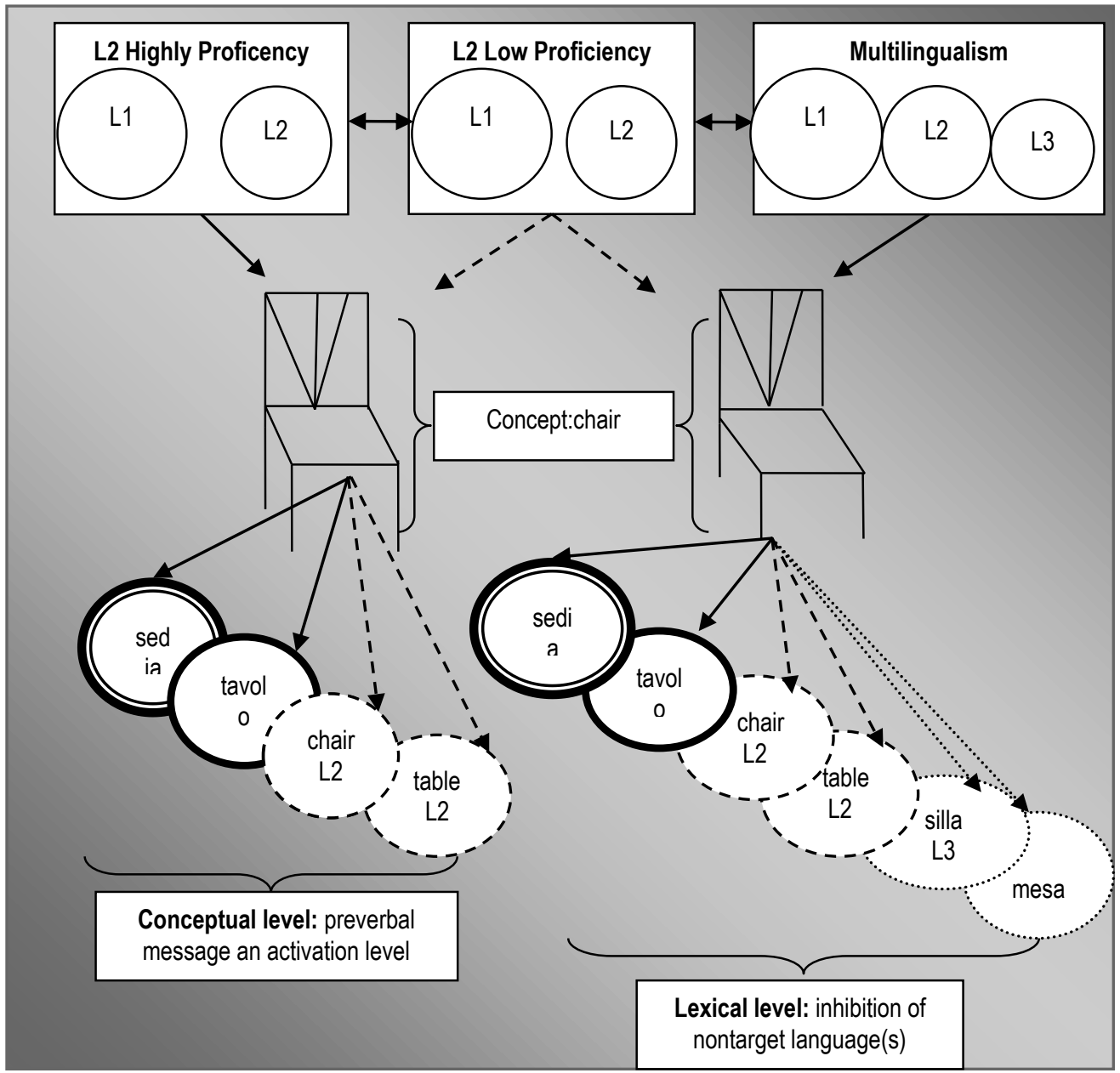

Figure 13.Language Selection by L2 Proficiency and Multilingualism Model

\section{References}

Allan, D. (1992). The Oxford Placement Test. Oxford: Oxford University Press.

Bloem, L. , and La Heij, W. (2003). Semantic facilitation and semantic interference in word translation: Implications for models of lexical access in language production. Journal of Memory and Language, 48, p. 468-488.

Caramazza, A. (1997). How many levels of processing are there in lexical access? Cognitive Neuropsychology, 14 (1), p. 177-208. 
Costa, A. (2005). Lexical access in bilingual production. In J. F. Kroll and A. M. B. de Groot (Eds. ), Handbook of bilingualism: Psycholinguistic approaches (p. 308-325). New York: Oxford.

Costa, A. and Santesteban, M. (2004). Lexical access in bilingual speech production: Evidence from language switching in highly proficient bilinguals and L2 learners. Journal of Memory and Language, 50, p. 491-511.

Costa, A. , Miozzo, M. , and Caramazza, A. (1999). Lexical selection in bilinguals: Do words in the bilinguals' two lexicons compete for selection? Journal of Memory and Language, 41,p. 365-397.

De Bot, K. (1992). A bilingual production model: Levelt's speaking model adapted. Applied Linguistics, 13, p. 1-24.

Demiray, F. (2014). Language Selectivity in Lexical Access: An Experimental Study on Bilinguals. Unpublished Phd Dissertation, Ankara University Social Sciences Institute. Ankara.

Fishman, J. A. (2001). 300-plus years of heritage language education in the United States. In J. K. Peyton, D. A. Ranard, and S. McGinnis (Eds. ), Heritage languages in America: Preserving a national resource (p. 81-97). Washington, DC and McHenry, IL: Center for Applied Linguistics and Delta Systems.

Francis S. W. (2000). Bilingual Semantic and Conceptual Representation. The University of Texas: El Paso.

Green, D. W (1998). Mental control of the bilingual lexico-semantic system. Bilingualism: Language and Cognition, 1,p. 6781.

Kroll, J. , Bobb, S. , and Wodniecka, Z. (2006). Language selectivity is the exception, not the rule: Arguments against a fixed locus of language selection in bilingual speech. Bilingualism: Language and Cognition, 9 (2), p. 119-135.

Kroll, J. F. ,and De Groot, A. M. B. (1997). Lexical and conceptual memory in the bilingual. A. M. B. De Groot, and J. F. Kroll (Eds. ) In, Tutorials in bilingualism: Psycholinguistic perspectives (p. 169-199). Mahwah, NJ: Lawrence Erlbaum Associates.

Kroll, J. F. , and Stewart, E. (1994). Category interference in translation and picture naming: Evidence for asymmetric connections between bilingual memory representations. Journal of Memory and Language, 33, p. 149-174.

La Heij, W. (2005). Selection processes in monolingual and bilingual lexical access. In J. F. Kroll and A. M. B. de Groot (Eds. ),Handbook of bilingualism: Psycholinguistic approaches (p. 289-307). New York: Oxford.

Levelt, W. J. M. (2001). Spoken word production: A theory of lexical access. Proceedings of the National Academy of Sciences, 98, p. 13464-13471.

Marian, F. , Blumenfeld, H. , and Kaushanskaya, M. (2007). The Language Experience and Proficiency Questionnaire (LEAP-Q): Assessing Language Profiles in Bilinguals and Multilinguals: Journal of Speech, Language, and Hearing Research, Vol. 50, p. 940-967.

Meuter, R. F. I. , and Allport, A. (1999). Bilingual language switching in naming: Asymmetrical costs of language selection. Journal of Memory and Language, 40, p. 25-40.

Schwieter, J. (2007). A psycholinguistic investigation of language selectivity in bilingual speech production. Phd Dissertation, 68 (9), Florida University. (UMI No. 3282661).

\section{Appendix A}

\section{Target words and stimuli used in Experiment 1 for L1 Turkish Participants}

\begin{tabular}{|l|l|l|l|l|l|}
\hline $\begin{array}{l}\text { Target } \\
\text { Word }\end{array}$ & $\begin{array}{l}\text { Translation } \\
\text { (produced) }\end{array}$ & $\begin{array}{l}\text { Related Context (picture or word } \\
\text { distracter) }\end{array}$ & $\begin{array}{l}\text { Unrelated Context (picture or word } \\
\text { distracter) }\end{array}$ \\
\hline Pig & Domuz & Keçi & Goat & Cetvel & Ruler \\
\hline Horse & At & Inek & Cow & Çorap & Sock \\
\hline
\end{tabular}




\begin{tabular}{|c|c|c|c|c|c|}
\hline Duck & Ördek & Tavuk & Chicken & Sepet & Basket \\
\hline Donkey & Eşek & Zebra & Zebra & Araba & Car \\
\hline Dog & Köpek & Kedi & Cat & Şeftali & Peach \\
\hline Deer & Geyik & Bufalo & Buffalo & Bluz & Blouse \\
\hline Tree & Ağaç & Yaprak & Leaf & Dudak & Lips \\
\hline Frog & Kurbağa & Salyangoz & Snail & Kol & Arm \\
\hline Ant & Karınca & Örümcek & Spider & Kapı & Door \\
\hline Shark & Köpekbalığı & Yunus & Dolphin & Zincir & Chain \\
\hline Plane & Uçak & Tren & Train & Burun & Nose \\
\hline Garlic & Sarımsak & Soğan & Onion & Ceket & Coat \\
\hline Grapes & Uzüm & Limon & Lemon & Yunus & Dolphin \\
\hline Rabbit & Tavşan & Sincap & Squirrel & Limon & Lemon \\
\hline Cherry & Kiraz & Elma & Apple & Zebra & Zebra \\
\hline Orange & Portakal & Şeftali & Peach & Kedi & Cat \\
\hline Ear & Kulak & Dudak & Lips & Solucan & Snail \\
\hline Spoon & Kaşık & Çatal & Fork & Sincap & Squirrel \\
\hline Scissors & Makas & Cetvel & Ruler & Yaprak & Leaf \\
\hline Glove & Eldiven & Çorap & Sock & Tavuk & Chicken \\
\hline Saw & Testere & Çekiç & Hammer & Elma & Apple \\
\hline Knife & Bıçak & Balta & Axe & Tren & Train \\
\hline Trousers & Pantalon & Hırka & Cardigan & Inek & Cow \\
\hline Dress & Elbise & Bluz & Blouse & Keçi & Goat \\
\hline Skirt & Etek & Ceket & Coat & Çekiç & Hammer \\
\hline Rope & Halat & Zincir & Chain & Örümcek & Spider \\
\hline Leg & Ayak & Kol & Arm & Soğan & Onion \\
\hline Eye & Göz & Burun & Nose & Balta & Axe \\
\hline Bike & Bisiklet & Araba & Car & Divan & Couch \\
\hline Suitcase & Valiz & Sepet & Basket & Çatal & Fork \\
\hline Window & Pencere & Kapı & Door & Hırka & Cardigan \\
\hline Chair & Sandalye & Divan & Couch & Bufalo & Buffalo \\
\hline
\end{tabular}

\section{Appendix B}


Target words and stimuli used in Experiment 1 for L1 Italian Participants

\begin{tabular}{|c|c|c|c|c|c|}
\hline \multirow{2}{*}{$\begin{array}{l}\text { Target Word } \\
\text { Pig }\end{array}$} & \multirow{2}{*}{\begin{tabular}{|l|}
$\begin{array}{l}\text { Translation } \\
\text { (produced) }\end{array}$ \\
Maiale
\end{tabular}} & \multicolumn{2}{|c|}{$\begin{array}{l}\text { Related Context (picture or word } \\
\text { distracter) }\end{array}$} & \multicolumn{2}{|c|}{$\begin{array}{l}\text { Unrelated Context (picture or word } \\
\text { distracter) }\end{array}$} \\
\hline & & Capra & Goat & Righello & Ruler \\
\hline Horse & Cavallo & Mucca & Cow & Calzino & Sock \\
\hline Duck & Anatra & Pollo & Chicken & Cestino & Basket \\
\hline Donkey & Asino & Zebra & Zebra & Macchina & Car \\
\hline Dog & Cane & Gatto & Cat & Pesca & Peach \\
\hline Deer & Cervo & Bufalo & Buffalo & Camicetta & Blouse \\
\hline Tree & Albero & Foglia & Leaf & Labbro & Lips \\
\hline Frog & Rana & Lumaca & Snail & Braccio & Arm \\
\hline Ant & Formica & Ragno & Spider & Porta & Door \\
\hline Shark & Squalo & Delfino & Dolphin & Catena & Chain \\
\hline Plane & Aereo & Treno & Train & Naso & Nose \\
\hline Garlic & Aglio & Cipolla & Onion & Cappotto & Coat \\
\hline Grapes & Uva & Limone & Lemon & Delfino & Dolphin \\
\hline Rabbit & Coniglio & Scoiattolo & Squirrel & Limone & Lemon \\
\hline Cherry & Ciliegia & Mela & Apple & Zebra & Zebra \\
\hline Orange & Arancione & Pesca & Peach & Gatto & Cat \\
\hline Ear & Orecchio & Labbro & Lips & Lumaca & Snail \\
\hline Spoon & Cucchiaio & Forchetta & Fork & Scoiattolo & Squirrel \\
\hline Scissors & Forbici & Righello & Ruler & Foglia & Leaf \\
\hline Glove & Guanto & Calzino & Sock & Pollo & Chicken \\
\hline Saw & Sega & Martello & Hammer & Mela & Apple \\
\hline Knife & Coltello & Ascia & Axe & Treno & Train \\
\hline Trousers & Pantaloni & Cardigan & Cardigan & Mucca & Cow \\
\hline Dress & Vestire & Camicetta & Blouse & Capra & Goat \\
\hline Skirt & Gonna & Cappotto & Coat & Martello & Hammer \\
\hline Rope & Corda & Catena & Chain & Ragno & Spider \\
\hline Leg & Gamba & Braccio & Arm & Cipolla & Onion \\
\hline Eye & Occhio & Naso & Nose & Ascia & $A x e$ \\
\hline Bike & Bicicletta & Macchina & Car & Divano & Couch \\
\hline
\end{tabular}




\begin{tabular}{|l|l|l|l|l|l|}
\hline Suitcase & Valigia & Cestino & Basket & Forshetta & Fork \\
\hline Window & Finestra & Porta & Door & Cardigan & Cardigan \\
\hline Chair & Sedia & Divano & Couch & Bufalo & Buffalo \\
\hline
\end{tabular}

